\title{
Barotropic Zonal Jets Induced by Islands in the Southwest Pacific
}

\author{
Xavier Couvelard, Patrick Marchesiello, Lionel Gourdeau, and Jerome Lefìvre \\ IRD, Noumea, New Caledonia
}

(Manuscript received 27 August 2007, in final form 4 February 2008)

\begin{abstract}
The oceanic circulation entering the tropical southwest Pacific (SWP) is dominated by the broad westward flow of the South Equatorial Current (SEC), which is forced by the trade winds. It has been argued that the numerous islands of the SWP are able to restructure the SEC into a series of deep and narrow zonal jets, which control important pathways connecting equatorial and extraequatorial signals. The primary objective of this paper is to improve the understanding of the structure and dynamics of SWP zonal jets, giving special attention to topographic effects. This study is based on the use of a high-resolution regional oceanic model, whose solution is compared with observations, as well as with solutions from global models and the Sverdrup relation. The model used here indicates that the regional topography drives a general equatorward shift of the SEC, which is beneficial to the North Fiji, North Vanuatu, and North Caledonian jets. A depth-integrated vorticity budget shows that this topographic effect is considerably attenuated by baroclinicity and advection processes, but not to the point of total compensation as often admitted for the interior ocean. The effect of nonlinear advection is to allow flow rectification of the jets fluctuations, taking the form of zonally elongated dipole circulations in the leeward side of the islands.
\end{abstract}

\section{Introduction}

The oceanic circulation in the tropical southwest Pacific (SWP) is dominated by the broad westward flow of the South Equatorial Current (SEC), forced by the trade winds. The SEC, which is the northern branch of the subtropical gyre, splits on the Australian coast to feed two western boundary currents: the southward East Australian Current (EAC) and the northward North Queensland Current (NQC). Many authors (e.g., Huang and Liu 1999; Luo et al. 2003; Fukumori et al. 2004) argue that the South Pacific circulation is a crucial element of decadal changes in the equatorial ocean. In particular, it was shown by Bratcher and Giese (2002) and Giese et al. (2002) that the southwest Pacific is an important pathway for connecting equatorial and extraequatorial signals.

The SWP has one of the world's most complex bottom topography, with numerous islands, ridges, and trenches (Fig. 1). This geometry is generally meridionally orientated, in contrast with the zonal large-scale

Corresponding author address: Patrick Marchesiello, IRD, Noumea Center, BP A5, 98848 Noumea CEDEX, New Caledonia.

E-mail: patrick.marchesiello@ird.fr flow entering the region, and the major Coral Sea islands (Fiji, Vanuatu, and New Caledonia) are major obstacles to the large-scale flow. Using a global numerical model [the U.K. Ocean Circulation and Advanced Modeling Project (OCCAM) at $1 / 4^{\circ}$ resolution], Webb (2000) shows that the islands of the SWP are able to restructure the SEC into a series of deep, narrow jets. In this model, five jets are identified (Fig. 2): the South and North Fiji jets (hereafter SFJ and NFJ), the North Vanuatu jet (NVJ), and the South and North Caledonian jets (SCJ and NCJ). However, few studies relate observational evidence of the SWP jets' existence, and the most direct evidence comes from recent observations by Gourdeau et al. (2008). Using direct current measurements across the Coral Sea, they confirm the existence of deep, narrow zonal jets north of New Caledonia and north of Vanuatu, and they also show evidence of eastward branches of jet recirculation between these two main currents. Hughes (2002) provides more indirect evidence; looking at zonal anomalies of Rossby wave propagation speed in altimetry data, he finds good spatial correlation with Webb's (2000) modeled barotropic jets. On a smaller scale, using hydrographic data, Stanton et al. (2001) reveal the presence of a shallow zonal jet south off Fiji (between Fiji and Kandavu) with a meridional width of less than half a degree. Re- 


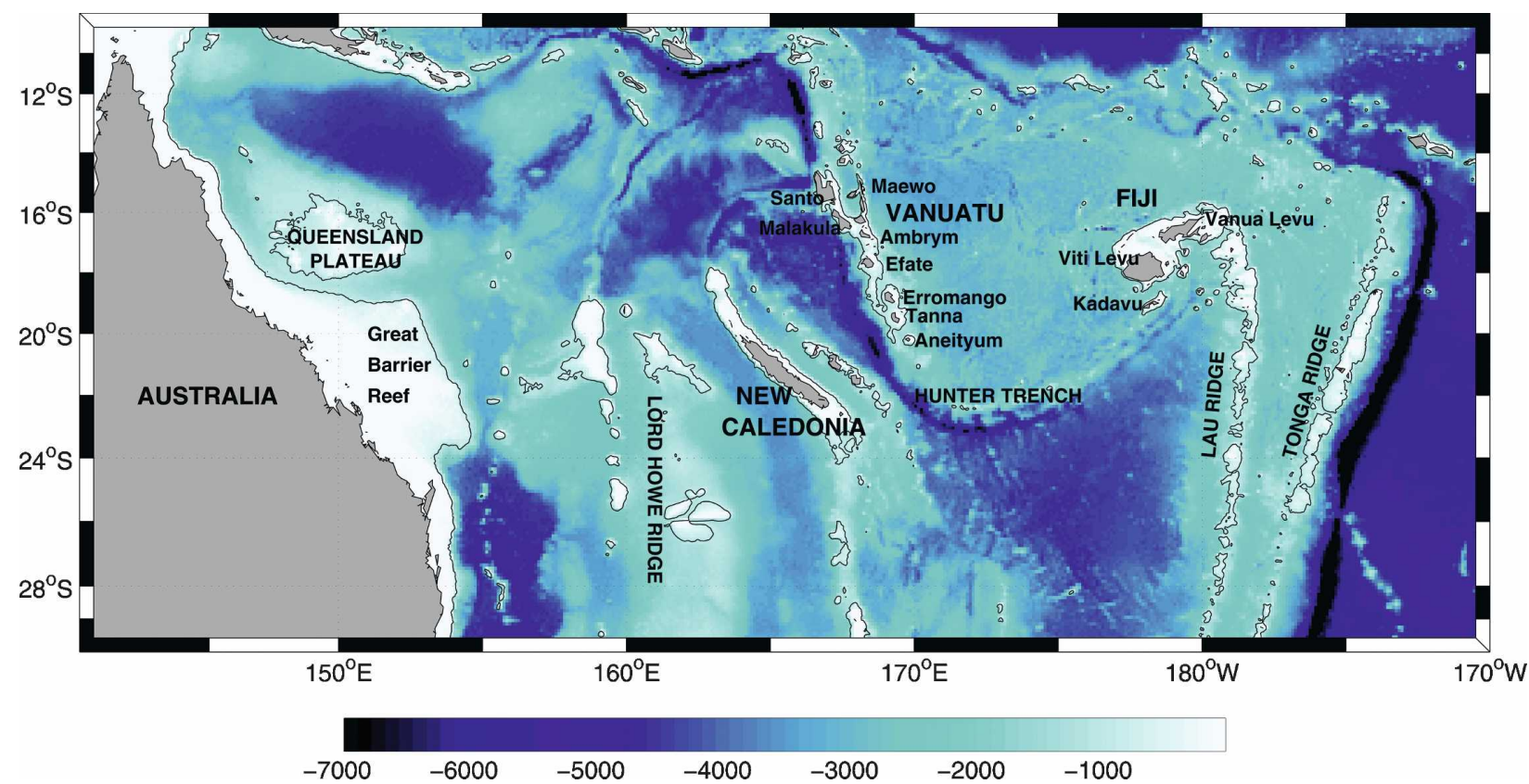

FIG. 1. Geography of the southwest Pacific region. The topography is essentially steep, rugged, and meridionally oriented.

gional climatology, compiled from historical hydrologic data [Commonwealth Scientific and Industrial Research Organisation (CSIRO) Atlas of Regional Seas (CARS); Dunn and Ridgway 2002], also points to the presence of large-scale zonal jets in the SWP. The barotropic streamfunction constructed from this climatology shows large zonal currents altered by the presence of the islands, but the "jets" are not as clearly defined as they are in models because of the inherent smoothness of the climatology. Nevertheless, we can retain from the available observations that the SEC transport seems to occur around latitudes that are farther north than pre- dicted by coarse large-scale global models or the Sverdrup balance.

The geometric effect has so far been reduced to the island mass effect (defined here as a two-dimensional obstacle to the flow), neglecting the forcing nature of the topographic slope. Aside from the effect of geometry, but on the Pacific scale, the literature on deep zonal jets has emphasized the role of nonlinear dynamical interactions (Nakano and Hasumi 2005; Richards et al. 2006). However, the residual expression of eddies has not been investigated at the regional scale in the SWP. In this paper, we propose to investigate the con-

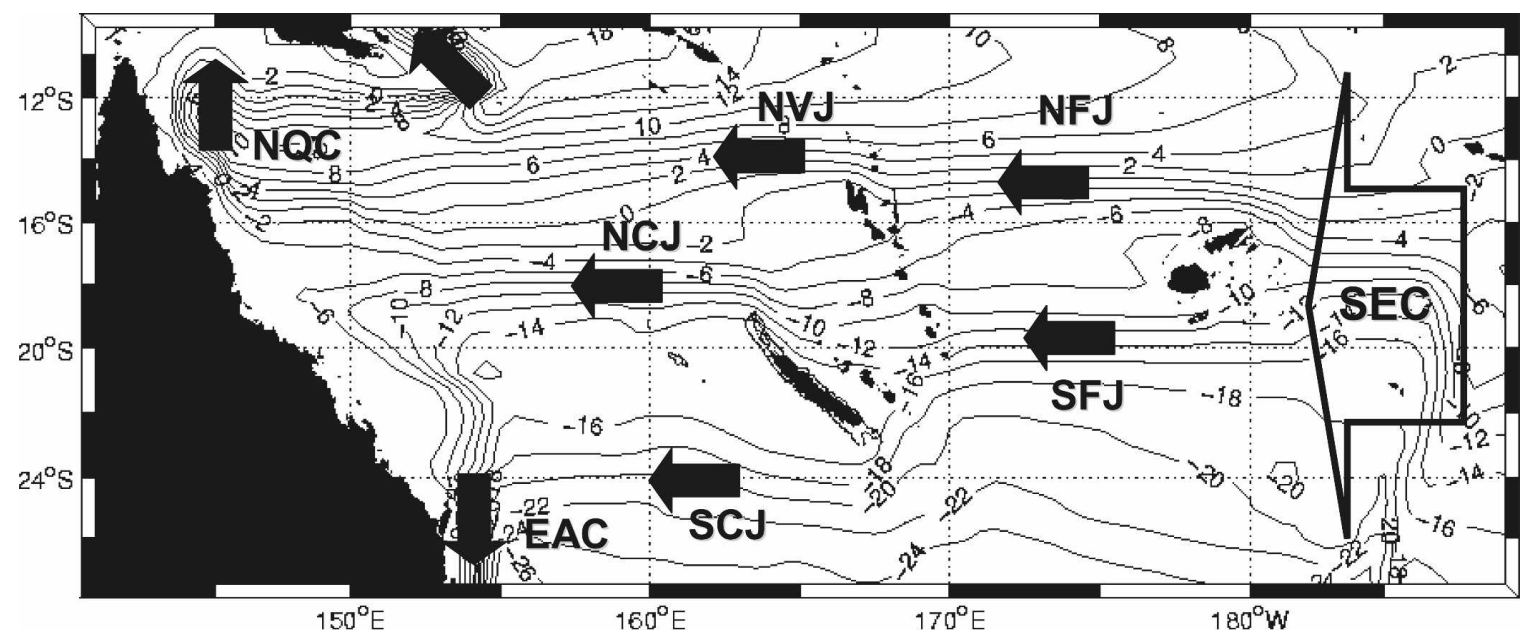

FIG. 2. Barotropic streamfunction from ORCA05. The zonal jets and main currents corresponding to Webb's (2000) identification are represented, namely, the SEC, NFJ, SFJ, NVJ, NCJ, SCJ, EAC, and NQC. 
tributions of geometry and advection (both linear and nonlinear) to the formation of SWP zonal jets. We focus on the time-mean, depth-integrated flow to obtain a synthetic approach of the mechanisms in which barotropic rectification and the topography-flow interaction are simple to express. One obvious caveat of large-scale models is the poor representation of interactions between bottom topography and ocean dynamics. Minimizing this interaction leads to a solution resembling the Sverdrup solution. A primary objective of this paper is therefore to evaluate the role of topography in generating barotropic SWP jets. Our demonstration is based on the use of a high-resolution regional model of oceanic circulation (presented in section 2) whose solution (section 4) is compared with the Sverdrup circulation (developed in section 3). In section 5, our analysis uncovers a major driving effect of bottom topography associated with the slope-related stretching effect. It also reveals the role of nonlinear advection on regional rectification of zonal jets.

\section{Model description}

The model employed in this study is the Regional Oceanic Modeling System (ROMS). For a complete description of the model, the reader is referred to Shchepetkin and McWilliams (2003, 2005). ROMS is a split-explicit, free-surface, and terrain-following vertical coordinate oceanic model, where short time steps are used to advance the surface elevation and barotropic momentum equation and where a much larger time step is used for temperature, salinity, and baroclinic momentum. ROMS employs a two-way time-averaging procedure for the barotropic mode, which satisfies the $3 \mathrm{D}$ continuity equation. The specially designed predictor-corrector time-step algorithm allows a substantial increase in the permissible time-step size. The thirdorder, upstream-biased, dissipative advection scheme for momentum allows the generation of steep gradients, enhancing the effective resolution of the solution for a given grid size (Shchepetkin and McWilliams 1998). For tracers, a fourth-order centered scheme is used along with geopotentially rotated hyperdiffusivity, to avoid excessive spurious diapycnal mixing associated with sigma coordinates. Explicit lateral viscosity is null everywhere in the model, except in sponge layers near the open boundaries where it increases smoothly on several grid points. A $K$-profile parameterization (KPP) boundary layer scheme (Large et al. 1994) parameterizes the subgrid-scale vertical mixing processes.

To encompass the topographic features most relevant to our circulation study of the SWP, we have designed a rectangular grid extending from $30^{\circ}$ to $10^{\circ} \mathrm{S}$ in latitude and from $141^{\circ}$ to $191^{\circ} \mathrm{E}$ in longitude. The model grid forcing initial and boundary conditions are built using the ROMSTOOLS package (Penven et al. 2007). The bottom topography is derived from a 2-foot resolution database ETOPO2 from National Oceanic and Atmospheric Administration/National Geophysical Data Center (NOAA/NGDC). Although a new pressure-gradient scheme associated with a modified equation of state limits computational errors of the pressure gradient (Shchepetkin and McWilliams 2003), the bathymetry still needs to be smoothed, so that the "slope parameter" $r=\Delta h / 2 h$ (Beckmann and Haidvogel 1993) is everywhere lower than 0.25 . To preserve a sufficient resolution in the upper ocean, we use 35 vertical levels with stretched $s$ coordinates, using surfaceand bottom-stretching parameters $\theta_{s}=6, \theta_{b}=0$ (Song and Haidvogel 1994). The surface layer resolution ranges from 1.4 to $15 \mathrm{~m}$ and a maximum grid size of 900 $\mathrm{m}$ is in the bottom layer.

The model external forcing is derived from observed and modeled climatology. At the surface, the model heat and freshwater fluxes are extracted from the Comprehensive Ocean-Atmosphere Data Set (COADS) ocean surface monthly climatology at $1 / 2^{\circ}$ resolution (Da Silva et al. 1994). The thermal feedback of the model ocean surface temperature to the surface heat flux is presented as a correction with respect to the COADS sea surface temperature as in Barnier et al. (1995). A similar correction is applied to the surface salinity flux. For momentum fluxes, a monthly mean wind stress climatology is computed and interpolated on the model grid, using the Quick Scatterometer (QuikSCAT) satellite scatterometer data for the period 1999 to 2006, provided by the Center for Satellite Exploitation and Research; (CERSAT; www.ifremer.fr/ cersat/en/index.htm) on a half-degree grid. At the three lateral boundaries facing the open ocean, a mixed passive-active, implicit, radiation condition connects the model solution to the surroundings (Marchesiello et al. 2001). In the case of inflow conditions, the solution at the boundary is nudged toward monthly time-averaged outputs of the ORCA05 global ocean model, which had been run on a $1 / 2^{\circ}$ resolution grid for the period 1992 to 2002 (Kessler and Gourdeau 2007; see barotropic streamfunction in Fig. 2). Forcing of interannual signals such as El Niño is explicitly excluded from this study, either at the surface or lateral open boundaries. Nevertheless, intrinsic interannual variability is allowed to generate in the model as a result of nonlinear instabilities of the large-scale circulation (Marchesiello et al. 2003). Finally, the model is initialized using Januarymean values from ORCA05 climatology.

The model was run in parallel on a 10-node PC clus- 
ter at high resolution $\left(1 / 12^{\circ}\right.$, i.e., about $\left.8 \mathrm{~km}\right)$ and in realistic mode using the full dynamical equations. More idealized configurations were also used, which allowed sensitivity analyses and a direct comparison of numerical and analytical solutions for the Sverdrup problem. The resolution sensitivity (at $1 / 2^{\circ}, 1 / 4^{\circ}, 1 / 6^{\circ}$, and $1 / 12^{\circ}$ resolutions) serves as a measure of the convergence level of the model solution. At $1 / 6^{\circ}$ resolution, some tests on the effect of bottom topography and nonlinearity are performed using a combination of approximations (linear or nonlinear, smooth or realistic topography). The spinup time for all simulations is $3 \mathrm{yr}$, and statistical analyses are performed using the following 7 yr of model integration.

\section{Sverdrup dynamics}

Before presenting our realistic solution, an exploration of the Sverdrup problem using both an analytic approach and the numerical model is valuable for later comparisons, and also as a cross-validation experiment.

\section{a. Analytical solution with island rule}

The Sverdrup relation considers neither island mass constraints to the flow nor western coastal boundaries. The "island rule" of Godfrey (1989; see also Wajsowicz 1993; Qiu et al. 1997) attempts to correct this problem by considering mass flux conservation across zonal sections between coastal boundaries. The mass flux imbalance between zonal sections, produced by the latitudedependent Sverdrup transport, is compensated for by the existence of western boundary currents. Continuity of these western boundary currents around islands imposes the generation of zonal jets (Qiu et al. 1997). Our method for computing the Sverdrup streamfunction, corrected by the island rule in the presence of multiple islands, is derived from Wajsowicz (1993) and the reader is referred to this article for details.

To obtain a streamfunction value on each island, several assumptions are needed. First, to estimate the EAC and NQC transports, Tasmania, Australia, and Papua New Guinea are treated as one single island (New Zealand and the Loyalty Islands east of New Caledonia are ignored). Fiji is represented as a single island including the two main islands and ignoring the smaller ones. The Vanuatu archipelago is considered as two islands: a southern group composed of Erromango and Tanna (hereafter South Vanuatu), and a northern group composed of Efate, Malakula, Santo, Ambrym, and Maewo (hereafter North Vanuatu). This configuration for Vanuatu has proven to be more realistic in the cross-validation experiment (see section $3 b$ ). Moreover, with these assumptions, a simple island rule is needed to obtain streamfunction values along the western boundaries of Australia, Fiji, South Vanuatu, and New Caledonia; only one multiple island rule is needed, involving North Vanuatu and Fiji, to obtain a value for North Vanuatu.

The full Sverdrup solution with islands is computed using the same QuikSCAT wind stress as for the numerical model (section 2). This solution, presented in Fig. 3, provides a steady, barotropic, inviscid, linear solution, assuming infinite-depth bathymetry with island obstacles. The computed streamfunction value on the Australian border is $-13 \mathrm{~Sv}\left(1 \mathrm{~Sv} \equiv 10^{6} \mathrm{~m}^{3} \mathrm{~s}^{-1}\right)$, which is in agreement with the value of $-16 \pm 4 \mathrm{~Sv}$ obtained by Godfrey (1989) using Hellerman and Rosenstein (1983) wind climatology (by comparing solutions using winds from QuikSCAT and European Remote Sensing Satellite (ERS-2), we have estimated an uncertainty of $\pm 2 \mathrm{~Sv}$; more generally, the analytical solution appears weakly sensitive to particular choices of available largescale wind data). This value implies a net northward transport of $13 \mathrm{~Sv}$ compensating for the Indonesian Throughflow. Streamfunction values for the islands are $-15 \mathrm{~Sv}$ for New Caledonia, $-11 \mathrm{~Sv}$ for South Vanuatu, -4 Sv for North Vanuatu, and -7 Sv for Fiji.

In Fig. 3, we see that the Sverdrup solution with island rule features all the zonal jets highlighted by Webb (2000), namely, the NFJ, SFJ, NVJ, NCJ, and SCJ, and can add to this picture the presence of a weak South Vanuatu Jet (SVJ) and a Vanuatu Throughflow (VT). More precisely, the SEC first splits around Fiji to give NFJ and SFJ transports of 2 and 4 Sv, respectively. The NFJ splits around North Vanuatu, contributing to the NVJ (5 Sv) in the north and the VT (4 Sv) in the south. The SFJ splits around South Vanuatu to feed the VT and a weak SVJ (2 Sv). The VT flows westward along a zonal pathway north of New Caledonia. The SVJ shifts northward on the east coast of New Caledonia and joins the VT to form the NCJ, which is the most intense jet in the region with $10 \mathrm{~Sv}$. The SCJ results from direct interaction between the SEC and New Caledonia with no direct influence from the others jets; its transport is about $6 \mathrm{~Sv}$. The NVJ, NCJ, and SCJ are the three remaining jets in the Coral Sea. The NCJ is the only one that clearly results from interaction among different islands. Consequently, the SCJ and NVJ have a more diffuse zonal structure with streamlines completing them along their way to Australia. Our island rule computation (including Australia) also allows an estimate of EAC and NQC transports. The EAC transport is $22 \mathrm{~Sv}$ (at $26^{\circ} \mathrm{S}$ ); its main sources are the $\mathrm{NCJ}$ and SCJ from the east and also the subtropical gyre recirculation from the southeast. The NQC transport is 26 $\mathrm{Sv}$ (at $12^{\circ} \mathrm{S}$ ), and its main sources are the NVJ and part 

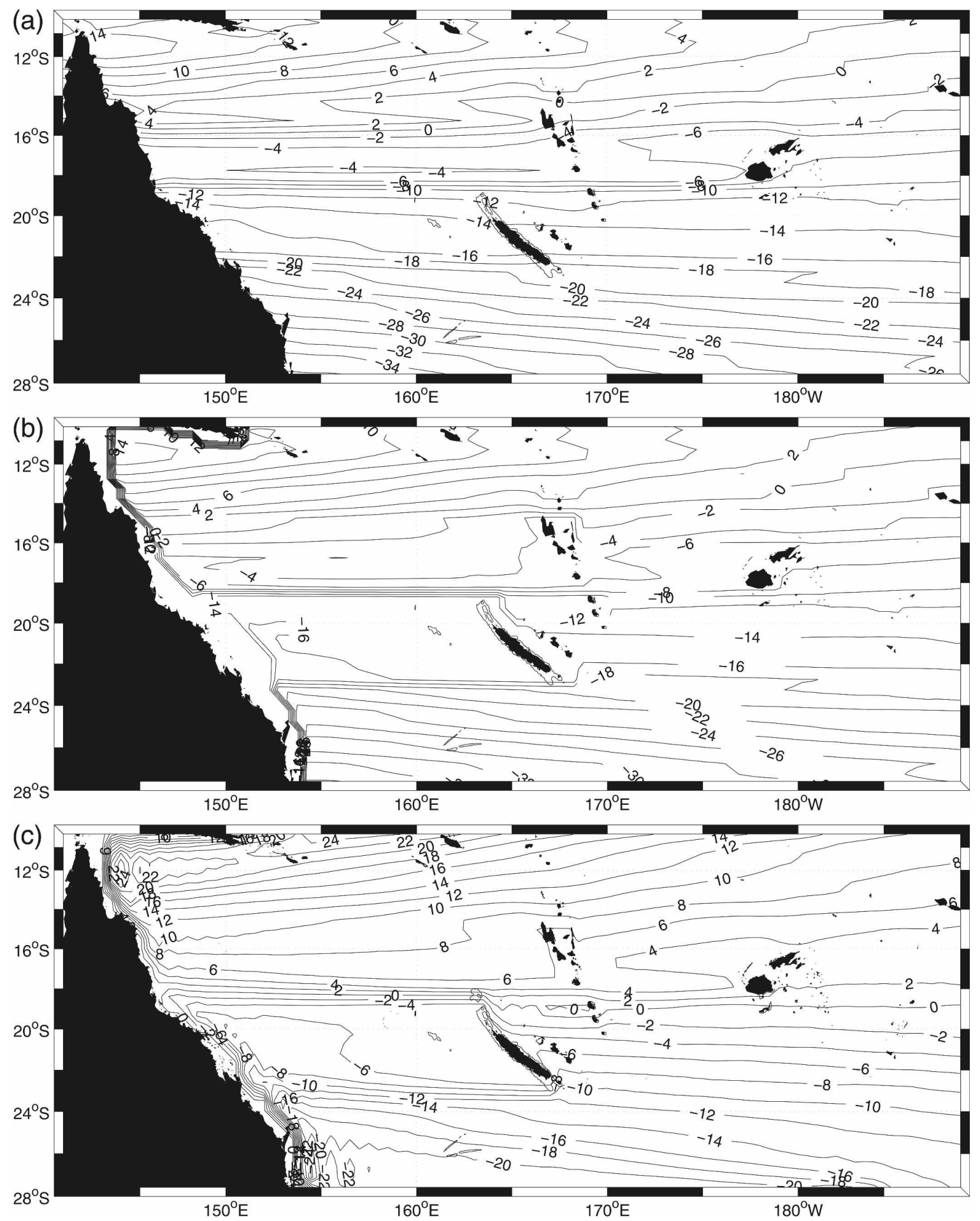

FIG. 3. Sverdrup streamfunction (Sv). (a) Analytical solution; (b) analytical solution with island rule; (c) numerical solution (ROMS flat-bottom linear configuration at $0.5^{\circ}$ resolution).

of the NCJ $(8 \mathrm{~Sv})$ from the east and also an inflow from the northern boundary.

$\mathrm{Qu}$ and Lindstrom (2002) argue that the strength of the equatorward-flowing NQC critically depends on the latitude where the SEC bifurcates at the western boundary and that the precise location of this bifurcation determines the amount of subtropical water transported to the tropics via the NQC. To evaluate the 


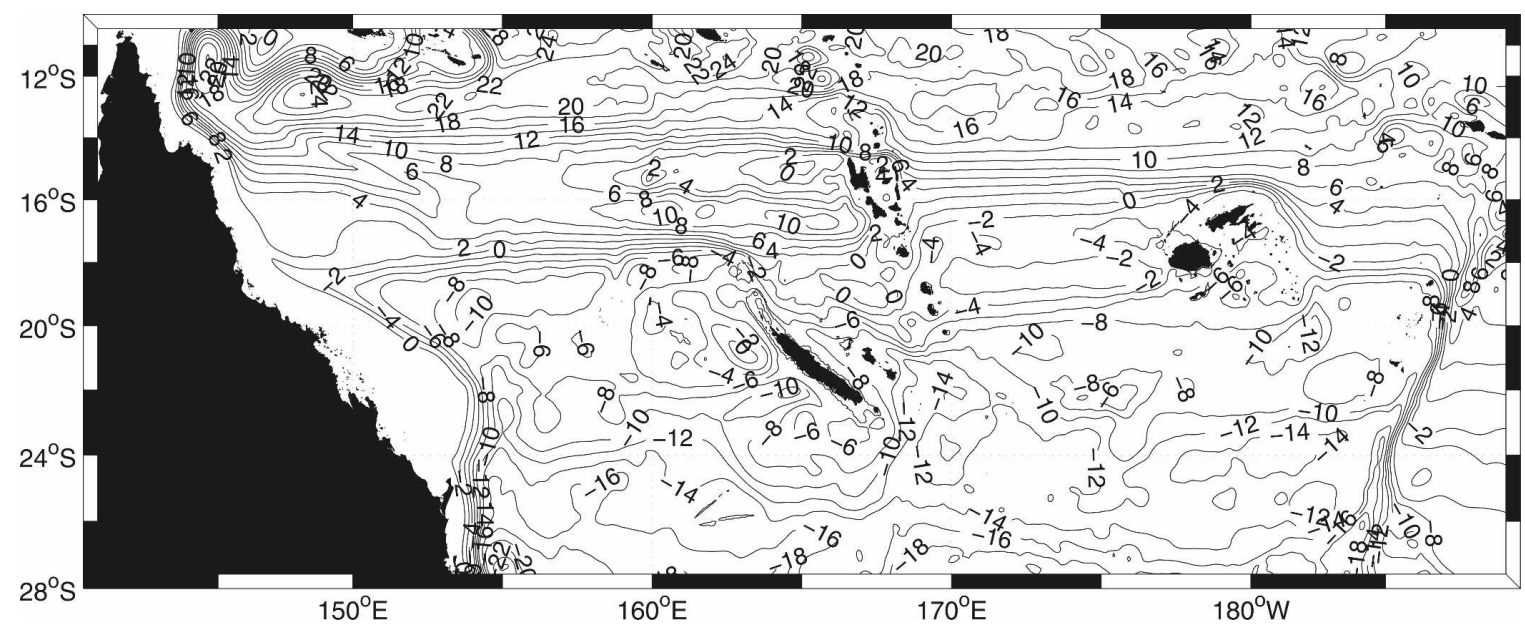

FIG. 4. ROMS mean barotropic streamfunction from the realistic simulation at $1 / 12^{\circ}$ grid resolution.

possible effect of the islands in modifying the latitude of bifurcation, a Sverdrup streamfunction was computed without consideration of the islands, with the exception of Australia. We can see by comparing Figs. 3a,b that the islands, in particular New Caledonia, induce a northward shift of $1^{\circ}$ on the bifurcation latitude but that the EAC and NQC transports do not change. The island rule can explain this result by showing that the streamfunction value on the Australian border is not changed by the presence of islands. Even if the streamlines are shifted northward by New Caledonia, it only changes the circulation pattern of the NQC around the bifurcation latitude $\left(18^{\circ} \mathrm{S}\right)$. However, the transport of water properties may be significantly affected by the change in the position of zonal currents. It is also interesting to note that a small but nonnegligible part of the jetlike structures exist even without island obstacles. These structures are produced by local wind stress curl, which results from island blocking effects on the trade winds (Kessler and Gourdeau 2006).

\section{b. Numerical Sverdrup solution}

To cross validate the numerical and analytical models on Sverdrup theory, we choose to present the $1 / 2^{\circ}$ grid, flat-bottom linear simulation. On the one hand, we aim to validate the model in this simple configuration, making particularly sure that the open boundary conditions are properly set up; this choice of resolution is designed to keep surface wind forcing (from the same QuikSCAT product) and grid masking as close as possible to the analytical problem. On the other hand, the comparison between the two models will act as confirmation that our computation of the Sverdrup relation with multiple islands is correct. In the numerical model, the vertically integrated speeds are derived from the
ORCA05 streamfunction, which resembles the Sverdrup solution; barotropic velocities are computed for a flat-bottom ocean of a 3000-m depth.

In the model solution presented in Fig. $3 \mathrm{c}$ we recognize the major features of the analytical Sverdrup streamfunction (Fig. 3b). The NCJ and SCJ are well formed; their transports are $10 \mathrm{~Sv}$ and $8 \mathrm{~Sv}$, respectively, which almost match the analytical values (the SCJ is $2 \mathrm{~Sv}$ larger). The NVJ is very diffuse and its transport difficult to estimate; we obtain about $5 \mathrm{~Sv}$ as in the analytical solution. The SFJ is also comparable with $4 \mathrm{~Sv}$, and the presence of the NFJ is not very clear, again as in the analytical solution. The bifurcation latitude is properly placed at $18^{\circ} \mathrm{S}$. It leads to EAC and NQC transports of $22 \mathrm{~Sv}$ (at $26^{\circ} \mathrm{S}$ ) and $24 \mathrm{~Sv}$ (at $12^{\circ} \mathrm{S}$ ), that is, very similar to their analytical values (22 and 26 Sv, respectively). Looking at boundary transports, the inflows from eastern and northern boundaries resemble their analytical transport values with 26 and $10 \mathrm{~Sv}$; the southern boundary inflow presents a transport of 4 instead of $6 \mathrm{~Sv}$ in the analytical solution. The overall excellent agreement between model and numerical solutions validates our choice of lateral forcing (ORCA05 transports), which will also be used in realistic simulations; at the same time, the comparison confirms the adequacy of our analytical computation of the island rule.

\section{Realistic model solution}

\section{a. Description of the barotropic flow}

Figure 4 shows the barotropic streamfunction of the nonlinear, realistic topography model solution at $1 / 12^{\circ}$ resolution [obtained by inverting the Poisson equation $\Delta \psi=\mathbf{k} \cdot(\boldsymbol{\nabla} \times \mathbf{U})$ as in Penven et al. (2005]. The jets' 
TABLE 1. Transport (Sv), size (degrees), position (latitude of jet center), barotropic velocity $U_{\text {bar }}\left(\mathrm{cm} \mathrm{s}^{-1}\right)$. NCJ and NVJ are estimated at $158^{\circ} \mathrm{E}, \mathrm{SCJ}$ at $162^{\circ} \mathrm{E}$, and SFJ and $\mathrm{NFJ}$ at $173^{\circ} \mathrm{E}$.

\begin{tabular}{clrrrrr}
\hline \hline $\begin{array}{c}\text { Model } \\
\text { Resolution }\end{array}$ & Jets & SCJ & NCJ & NVJ & SFJ & NFJ \\
\hline $1 / 2^{\circ}$ & Transport & -9.5 & -13.5 & -6.4 & -13.2 & 0 \\
& Size & 1.8 & 2.9 & 1.0 & 2.4 & 0 \\
& $U_{\text {bar }}$ & -3.3 & -1.6 & -1.8 & -1.7 & 0 \\
& Position & -24.0 & -17.4 & -13.6 & -19.9 & 0 \\
$1 / 4^{\circ}$ & Transport & -7.6 & -13.8 & -8.8 & -12.8 & -7.7 \\
& Size & 2.3 & 3.3 & 1.5 & 2.3 & 1.7 \\
& $U_{\text {bar }}$ & -2.1 & -1.5 & -1.6 & -1.7 & -1.3 \\
& Position & -24.9 & -18.1 & -13.6 & -20.0 & -14.4 \\
$1 / 6^{\circ}$ & Transport & -8.6 & -11.0 & -13.5 & -11.7 & -11.3 \\
& Size & 1.8 & 1.9 & 2.1 & 2.2 & 2.1 \\
& $U_{\text {bar }}$ & -3.2 & -1.6 & -1.7 & -1.6 & -1.6 \\
& Position & -24.0 & -17.4 & -14.0 & -20.3 & $-14.6:$ \\
$1 / 12^{\circ}$ & Transport & -5.5 & -16.4 & -14.1 & -9.3 & -17.6 \\
& Size & 2.6 & 1.9 & 1.9 & 1.8 & 3.6 \\
& $U_{\text {bar }}$ & -1.4 & -2.0 & -1.8 & -1.6 & -1.6 \\
& Position & -23.8 & -17.5 & -14.0 & -19.6 & -15.4 \\
\hline
\end{tabular}

characteristics (transport, size, position, and barotropic velocity) are presented in Table 1 ; the NCJ and NVJ are estimated at $158^{\circ} \mathrm{E}, \mathrm{SCJ}$ at $162^{\circ} \mathrm{E}$, and $\mathrm{SFJ}$ and $\mathrm{NFJ}$ at $173^{\circ} \mathrm{E}$. The jet size is estimated here by calculating the radial distance to the jet axis where the jet velocity is reduced to a third of that of the jet axis velocity.

While the Sverdrup solution resembles the picture given by the $1 / 4^{\circ}$ solution of Webb (2000), that is, featuring essentially the same NFJ, SFJ, NVJ, NCJ, and SCJ, our realistic solution shows substantial differences. In particular, there is a general shift of the circulation, favoring a northward direction for western boundary currents along the islands associated with a preference for northern zonal jets against southern ones. Another general observation is the presence of significant recirculation jets in the leeward side of the islands.

In the eastern part of the domain, the SEC shifts northward, apparently under the influence of the Tonga Ridge. The bifurcation on Fiji neatly favors the NFJ (18 Sv) against the SFJ (9 Sv), with a strong, narrow, northward-flowing western boundary current of about $8 \mathrm{~Sv}$. In turn, the major part of the NFJ feeds a northward-flowing western boundary current along Vanuatu leading to the NVJ, and a weaker southward flow leading to the VT (as in the Sverdrup picture). The SFJ is driven south of the Vanuatu islands (SVJ), before turning north along the Loyalty Islands to feed the NCJ where it joins the VT and a contribution from the NVJ. The SFJ also contributes to a weak southward flow along New Caledonia; this can be recognized as the Vauban Current.
At this point, one can already note that the SCJ is particularly weak (5 Sv) and has lost its proper zonal direction. It seems that a large part of the flow is driven northward by steering by the Tonga, Lau, and Loyalty Ridges. West of New Caledonia and north of $18^{\circ} \mathrm{S}$ (the New Caledonia reef limit), the NVJ and NCJ are much stronger than in the Sverdrup solution, with transports of $14 \mathrm{~Sv}$ and $16 \mathrm{~Sv}$, respectively (compared to $5 \mathrm{~Sv}$ and $10 \mathrm{~Sv}$ ). The NVJ, which is very diffuse in the Sverdrup solution, is in the realistic solution almost as strong as the NCJ. Under the influence of the Queensland Plateau, the bifurcation latitude of the NCJ remains around $18^{\circ} \mathrm{S}$ but occurs eastward of the plateau, not on the Australian border (as in the Sverdrup case).

In the realistic model solution, dipoles of recirculation appear in the leeward side of the major islands. They are associated with eastward countercurrents in the islands' wakes, reminiscent of the countercurrent observed around Hawaii (Xie et al. 2001; Sasaki and Nonaka 2006).This aspect of the flow is pertaining to the nonlinear nature of the circulation (as will be shown in section 5) and contributes significantly to the increased transport of the jets. The recirculation cells are present leeward of each island, but the characteristics vary. In the wake of Fiji, the anticylonic, northernmost recirculation cell is weaker than its southern counterpart. The Vanuatu dipoles are more symmetrical and show a countercurrent transport of up to $10 \mathrm{~Sv}$ at its maximum. For both Fiji and Vanuatu, the zonal extension of these cells seems to be only limited by geometry. For New Caledonia, in contrast, the wake is composed of a more meridionally elongated cyclonic circulation, compressing a weak anticyclonic cell against the NCJ. This behavior can be related to topographic effects by the western slope of New Caledonia and the Lord Howe Rise (as will be shown in section 5).

\section{b. Model-data comparison}

The most complete compilation of historical hydrographic data in the SWP region is the CARS climatology (Dunn and Ridgway 2002). The CARS2000 data are interpolated on a half-degree grid, from the surface to $5000 \mathrm{~m}$, with 66 vertical levels. The barotropic streamfunction constructed from this climatology (Fig. 5) shows large zonal transports seemingly altered by the presence of the SWP islands, but the barotropic jets lack the clear definition that they have in models (there is better definition at a $200-\mathrm{m}$ depth, where the flow is similar in pattern to the barotropic flow as shown by Webb 2000). From the eastern part of the domain a broad westward flow representing the SEC can be seen. Near the longitude of the Tonga Ridge, the SEC shifts northward, becomes narrower, and then splits around 

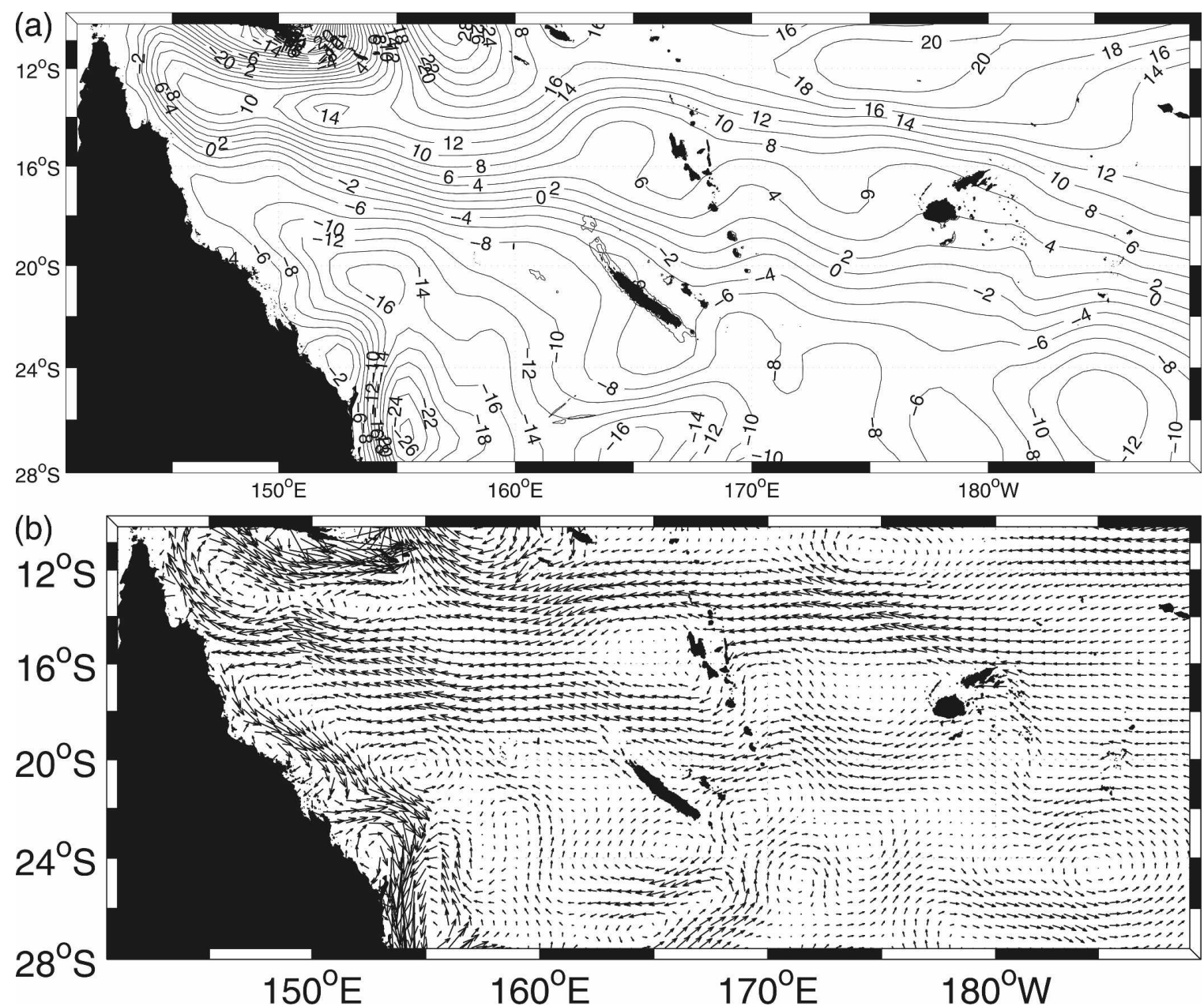

FIG. 5. (a) Barotropic streamfunction from CARS vertically integrated geostrophic velocity relative to $2000 \mathrm{~m}$. (b) Velocities at $200 \mathrm{~m}$.

both the Fiji and Vanuatu archipelagoes. On the Australian coast, the bifurcation latitude between EAC and NQC is estimated in both this and our model to occur eastward of the Queensland Plateau, at around $18^{\circ} \mathrm{S}$. The climatology is obviously too coarse and smooth to describe the flow in detail, but there is clear suggestion that the largest part of the SEC is to be found north of New Caledonia, in agreement with our realistic model but in discrepancy with the Sverdrup solution and coarse global models.

The model is forced at the lateral boundaries with ORCA05 model output. However, the open boundary conditions in ROMS allow for some adjustment of boundary transports depending on the direction of propagation of the dominant waves. At the eastern and southern boundaries, respectively, the dominant propagation of Rossby and coastally trapped waves are directed inside the domain. In this case, the boundaries are in forcing mode and the interior domain has to adjust to the westward-flowing SEC and southwardflowing EAC. On the contrary, for the northern boundary, the model solution tends to be extrapolated from the interior solution, producing its own estimation of the NQC. If both direct and indirect observational estimations of EAC transports are available (e.g., Mata et al. 2000; Ridgway and Dunn 2003, giving between 20 and $30 \mathrm{~Sv}$ around $30^{\circ} \mathrm{S}$ ), observations of the NQC are much scarcer. Models generally give transports between 15 and $25 \mathrm{~Sv}$ at $10^{\circ} \mathrm{S}$ (Kessler and Gourdeau 2007), which agrees with the present computation.

Spray glider number 1 was deployed on 17 July 2005 during the SECALIS-3 oceanographic cruise, just offshore of Guadalcanal Island in the southern Solomon Islands (Gourdeau et al. 2008). It was recovered 3 months later just outside the New Caledonian reef after covering a total distance of $1640 \mathrm{~km}$. Spray is an autonomous underwater glider that cycles vertically through the water column and uses lift on wings to 


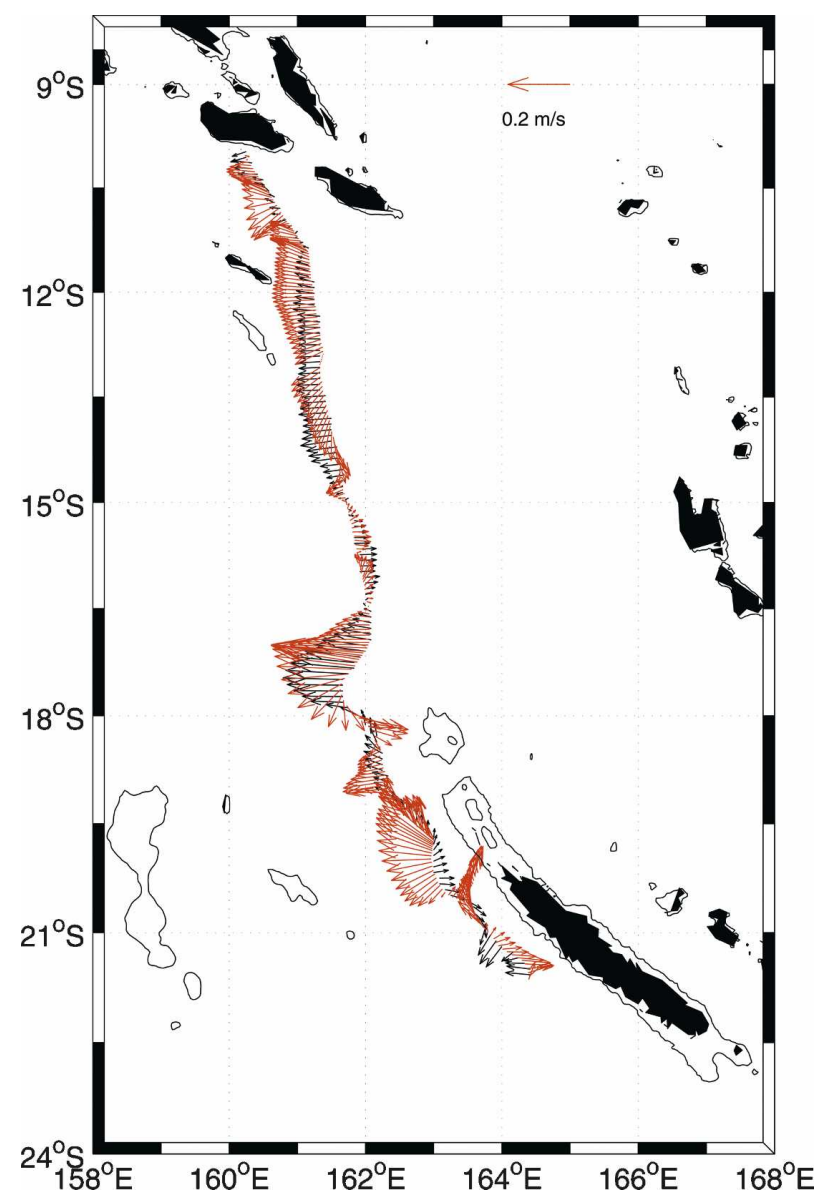

FIG. 6. Velocity comparison between spray glider data (red arrows) and ROMS output (black arrows). The velocities are depth averaged between 0 and $600 \mathrm{~m}$ along the glider track. The glider data were collected during the period July-September 2005 and have been low-pass filtered to remove the tides; the model velocities are interpolated from the 7-yr-averaged solution.

convert part of its vertical velocity in forward motion. It was equipped with a CTD to provide profiles of temperature and salinity for the first $600 \mathrm{~m}$ of the water column. Depth-averaged velocity was derived from the difference between vehicle motions as measured by GPS fixes and the distance traveled through the water. Using both the depth-averaged velocity and baroclinic geostrophic velocities computed from the glider CTD data, the first high-resolution measurements of absolute velocities between New Caledonia and the Solomon Islands were produced (see Gourdeau et al. 2008 for a complete description of the glider data acquisition). Here, we present a comparison between model and glider data of the depth-averaged subtidal velocities between 0 and $600 \mathrm{~m}$ (Fig. 6) and vertical sections of zonal velocities along the glider track (Fig. 7). The 7-yr-averaged model solution shows very similar patterns to the 3-month period of glider observations north of New Caledonia, suggesting that the depth-integrated flow structure in the Coral Sea is not dominated by its eddy component (although the latter is vigorous enough to produce flow rectification, as shown in section 5c). Both types of data present zonal, westwardflowing jets, the NCJ and NVJ, with a transition zone where the flow can be reversed and form a countercurrent. The observed jets' transports, estimated by Gourdeau et al. (2008), are 10 and $20 \mathrm{~Sv}$, respectively, for the $\mathrm{NCJ}$ and NVJ, which match almost exactly the model values. The meridional size of the jets is also in good agreement, and velocities are comparable with values near $30 \mathrm{~cm} \mathrm{~s}^{-1}$ in the NCJ and $15 \mathrm{~cm} \mathrm{~s}^{-1}$ in the NVJ, although model velocities tend to be weaker. One of the most interesting patterns is the transition zone between NCJ and NVJ. The model does a good job of reproducing the meridional extension of this transition, featuring a relatively weak mean eastward counterflow (less than $10 \mathrm{~cm} \mathrm{~s}^{-1}$ ), which is part of NVJ and NCJ recirculation cells. On the contrary, the southern part of the domain (south of $19^{\circ} \mathrm{S}$ ) presents large differences at the mesoscale level, suggesting higher turbulent energy. This is consistent with analyses by Hughes (2002) of satellite altimetry variability in the SWP region and the fact that the surface flow in the southern part of the domain opposes the jets and produces high levels of available potential energy for baroclinic instability.

We now compare ROMS mean currents (Fig. 7, middle) to the glider absolute geostrophic velocities (Fig. 7, top) in a vertical section along the glider track. The velocity field is smoother in the model, but the flow structure is comparable. In particular, the NCJ is larger and weaker in ROMS than in the data, but the -10 $\mathrm{m} \mathrm{s}^{-1}$ contours are very similar. Both model and data show a barotropic NCJ and more baroclinic NVJ, while the countercurrent centered at $15.5^{\circ} \mathrm{S}$ appears more baroclinic in the observations than in the model. Our interpretation is that the glider data may have captured a transient expression of the countercurrent, probably a baroclinic mesoscale eddy, but this point would need further examination. In any case, both the glider data and the model suggest that the northern jets have a coherent structure in the vertical direction over a large depth range (with maximum speed values in the main thermocline). This was recently confirmed by several Argo autonomous floats near $1000 \mathrm{~m}$, which were transported westward by strong, narrow jets corresponding to the NCJ and NVJ, with evidence of deep eastward recirculation (Maes et al. 2007).

In spite of the difficulty to find a set of data that is representative of the mean barotropic circulation, we feel that the model barotropic solution with its array of 

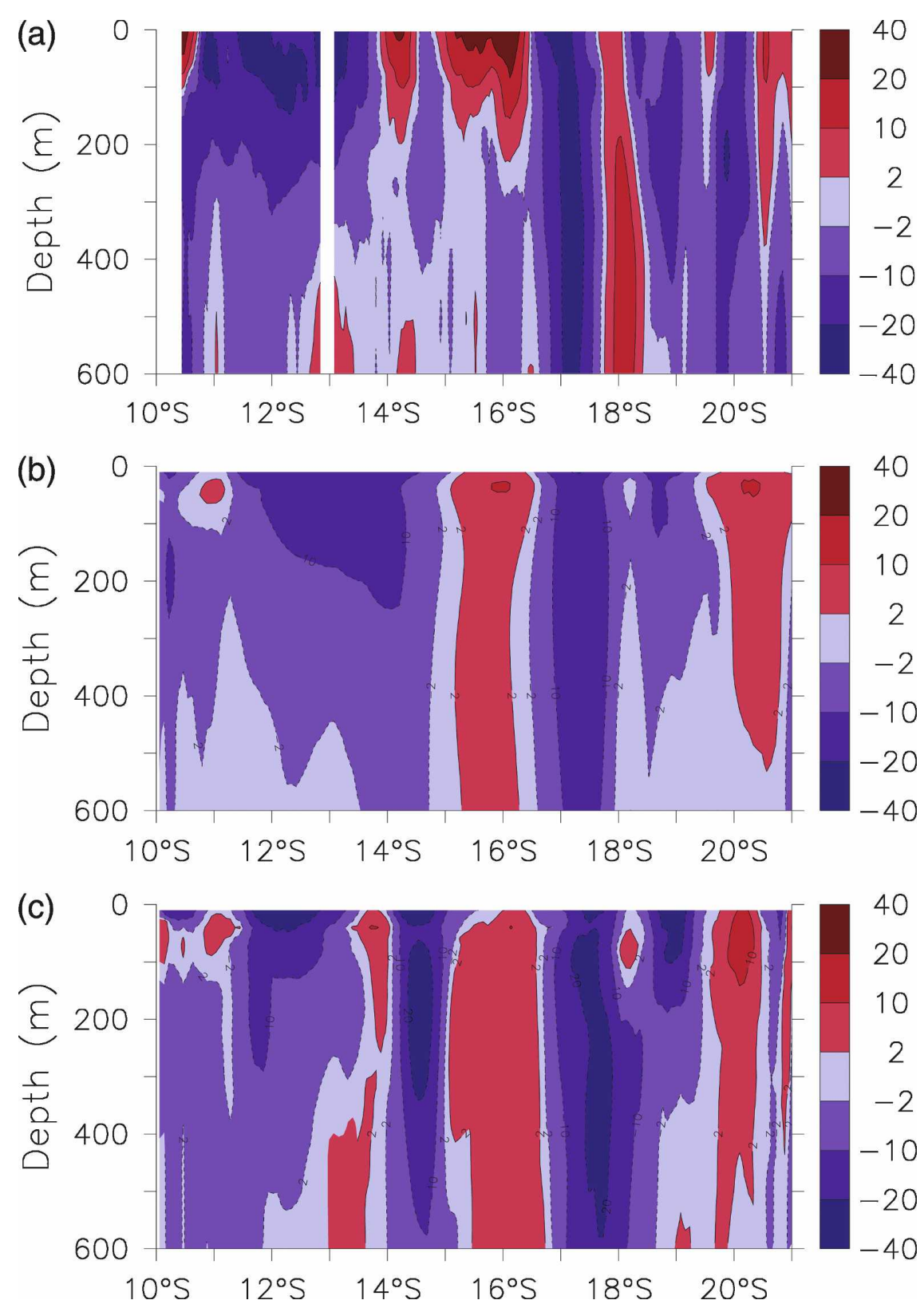

FIG. 7. (a) Zonal absolute velocity measured along the spray glider track deployed during July-September 2005 (Gourdeau et al. 2008); (b) July snapshot of ROMS zonal velocity along the glider track; (c) ROMS 7-yr mean zonal velocity along the glider track.

zonal jets is reasonably validated by our model-data comparison.

\section{c. Comparison with global high-resolution models}

In this study, we have chosen to use a terrainfollowing coordinate model as we are attempting to estimate the role played by the often neglected topographic steering effect. Although in recent years great improvements have been made in controlling their nu- merical errors, these types of models are still mostly used on smaller coastal problems rather than larger regional problems. We have previously seen that the OCCAM solution at $1 / 4^{\circ}$ resolution is more comparable to our low-resolution or even flat-bottom solutions, simply because the topography is not affecting the barotropic flow in a significant way. However, there is a possibility that the flow in our $s$-coordinate model study may be overaffected by topography due to un- 


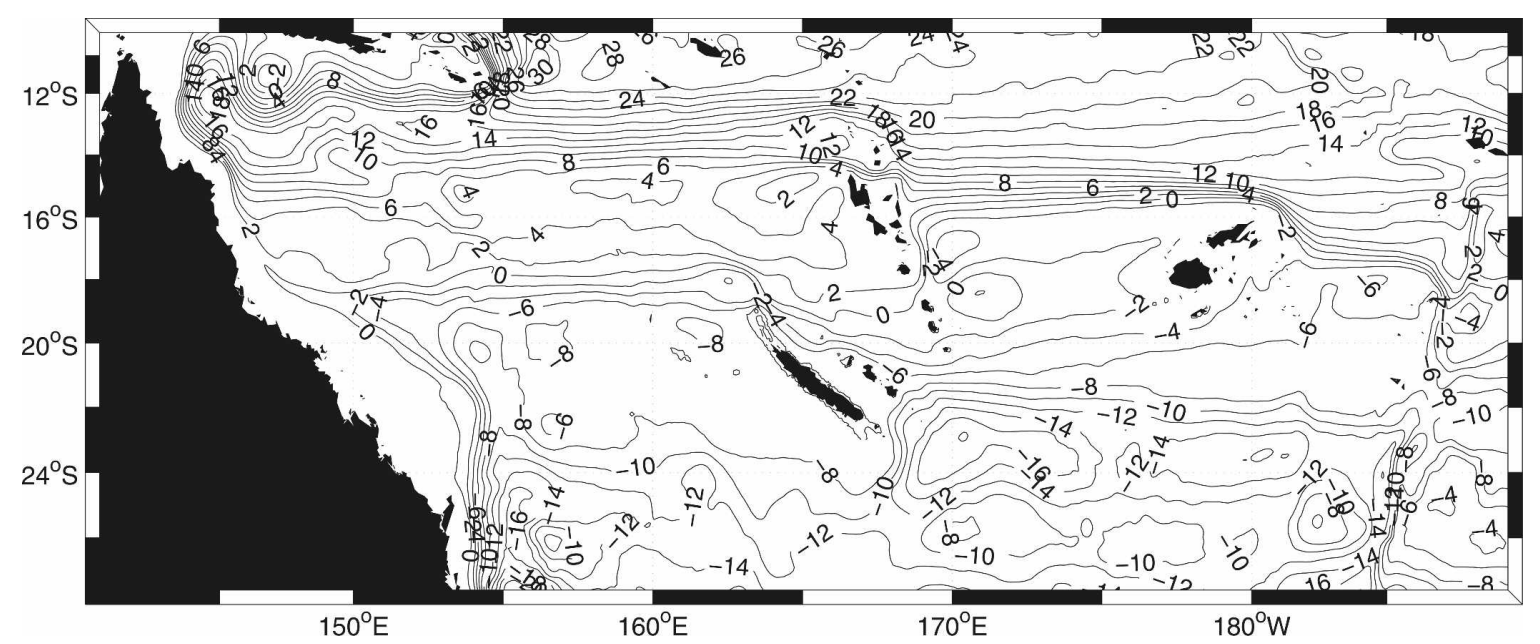

FIG. 8. Mean barotropic streamfunction in the high-resolution global model OCCAM (1992-2002 mean) at 1/12 ${ }^{\circ}$ resolution.

controlled numerical errors. A comparison with other types of models (geopotential coordinate models in particular) at higher resolution, where all types of models should converge, might give us confidence that our solution is realistic. For comparison, we use here the mean barotropic solution of OCCAM global geopotential coordinate model at $1 / 12^{\circ}$ (Lee et al. 2001). This simulation was run for model years 1988 to 1993 and presents the finest-resolution global solution available at this time. A quick validation of its water masses and circulation in the southwest Pacific has shown consistency of the OCCAM solution with large-scale data. In our model intercomparison, the barotropic streamfunctions of ROMS (Fig. 4) and OCCAM (Fig. 8) have similar patterns, with westward zonal jets dominating the flow north of New Caledonia and less zonally coherent circulations south of New Caledonia. Most of the westward flow is located north of Fiji, New Caledonia, and Vanuatu in both models; the jets have similar characteristics of meridional dimensions and transport.

The most important difference between ROMS and OCCAM lies in the recirculation cells in the lee of New Caledonia, Vanuatu, and Fiji, and south of New Caledonia. The recirculation cells are present in OCCAM west of Vanuatu and Fiji with a north-south asymmetry that was also pinpointed in our results. However, the strength of the recirculation cells is significantly lower. In the wake of New Caledonia, the comparison is even more dramatic because OCCAM does not present any recirculation pattern at all in its mean barotropic field. Southeast of New Caledonia, OCCAM presents stronger recirculation cells than in ROMS, but the pattern of circulation in both models is much less zonally coherent in the south than in the north. In particular, both solutions show an anticylonic trend modulating the SCJ off southwest New Caledonia, which is reminiscent of the pattern seen in the CARS climatology (Fig. 5).

It is beyond the scope of this study to fully analyze the sources of difference between the two models (lateral boundary forcing, accuracy of numerical techniques, topographic representation; see Coward and de Cuevas 2005 for a detailed description of OCCAM), but we conclude that the convergence between solutions is clear enough that the proposed ROMS simulation and its analysis are relevant to our understanding of the southwest Pacific circulation.

\section{Analysis}

The Sverdrup balance relates the wind-driven meridional transport in the ocean to the local curl of the wind stress: $\beta V=\operatorname{curl}\left(\tau^{w}\right)$, where $\beta=\partial f / \partial y$ is the meridional variation of planetary vorticity, $V$ is the meridional mass transport, and $\tau^{w}$ is the wind stress vector divided by the reference density $\rho_{0}$. The Sverdrup balance is exactly valid only over a linear, flat-bottom ocean. In reality, a topographic steering effect exists that tends to keep potential vorticity constant. In a homogenous ocean with variable topography $H$, the flow tends to follow constant lines of $f / H$, instead of zonal $f$ lines (in the flat bottom case). Conservation of $f / H$ requires that a flow passing over a ridge be deflected equatorward. This simple law explains qualitatively why the SEC has a tendency to a northward drift when encountering a ridge or island on its path. However, many authors (e.g., Cane et al. 1998; Gill 1982) argue that baroclinicity acts as a barrier to topographic steering, by strongly decreasing the bottom pressure gradients, which interacts with the topography. According to this view, the ocean interior is essentially in Sverdrup balance. We 
know that this proposition is not always true, particularly in areas where the barotropic component of the flow is strong, such as the Antarctic Circumpolar Current (Wells and de Cuevas 1995). In the southwest Pacific, the topography, particularly across zonal flows, is so steep and rugged that the Sverdrup balance is also a priori questionable. In addition, nonlinear advection has often been neglected in the vorticity budget. Therefore, we present in the following section an analysis of the full depth-integrated vorticity budget, completed by a series of sensitivity experiments.

\section{a. Depth-integrated vorticity budget}

First, the depth-integrated momentum primitive equations (with hydrostatic, Boussinesq approximations) in terms of depth-integrated velocity components $(U, V)$ is written as follows:

$$
\begin{aligned}
& \frac{D U}{D t}=f V-g H \frac{\partial \eta}{\partial x}-\phi_{x}+\tau_{x}^{w}-\tau_{x}^{b} \text { and } \\
& \frac{D V}{D t}=-f U-g H \frac{\partial \eta}{\partial y}-\phi_{y}+\tau_{y}^{w}-\tau_{y}^{b},
\end{aligned}
$$

where $\phi_{x}=\frac{g}{\rho_{0}} \int_{-H}^{0}\left(\int_{z}^{0} \frac{\partial \rho}{\partial x} d z^{\prime}\right) d z \quad$ and

$$
\phi_{y}=\frac{g}{\rho_{0}} \int_{-H}^{0}\left(\int_{z}^{0} \frac{\partial \rho}{\partial y} d z^{\prime}\right) d z
$$

and where $\phi, \tau^{w}$, and $\tau^{b}$ are the depth-integrated pressure gradient (divided by the reference density), wind stress, and bottom stress vectors, respectively. Their components in Cartesian coordinates are noted by $x$ and $y$ indices. Here, $\eta$ is surface elevation, $\rho$ is density, $g$ is gravity acceleration, and $H$ is bottom depth. Crossdifferentiating Eq. (1), we obtain the depth-integrated vorticity equation

$$
\begin{aligned}
\frac{\partial \xi}{\partial t}+\beta V= & \operatorname{curl}\left(\tau^{w}\right)-[g J(\eta, H)+\operatorname{curl}(\phi)] \\
& -\operatorname{curl}(\mathrm{Adv})-\operatorname{curl}\left(\tau^{b}\right), \\
\text { where curl }(\mathrm{Adv})= & \frac{\partial}{\partial x} \int_{-H}^{0}\left(\frac{\partial u v}{\partial x}+\frac{\partial v v}{\partial y}\right) d z \\
& -\frac{\partial}{\partial y} \int_{-H}^{0}\left(\frac{\partial u u}{\partial x}+\frac{\partial u v}{\partial y}\right) d z
\end{aligned}
$$

$J$, and curl are the Jacobian and vertical curl operators, respectively. The vorticity advection term curl(Adv) is the curl of the vertically integrated momentum advection terms (written in terms of the three-dimensional horizontal velocity $(u, v)$. We can group the baroclinic and barotropic pressure terms, which are equal to the bottom pressure torque (BPT): $J\left(P_{b}, H\right)=g J(\eta, H)+$ $\operatorname{curl}(\phi)$, where $P_{b}$ is the bottom pressure.

We now consider that all terms of this equation are averaged in time over a period long enough that time derivatives of time-mean quantities are zero. The remaining term on the left-hand side will be called beta and is positive when the meridional transport is positive. Each of the terms on the right-hand side of (2) may be considered separately as a contribution to the mean meridional transport. These terms will be referred to as wind curl, BPT, advection, and bottom friction. The last three terms are representing the departure from Sverdrup balance, caused by topographic steering, advection, and bottom friction. The advection term can be further split between turbulent and time-averaged contributions, written as functions of mean and turbulent currents (defined by $u=\bar{u}+u^{\prime}$ and $v=v+v^{\prime}$ ):

$$
\begin{aligned}
\operatorname{curl}(\mathrm{Adv})= & \frac{\partial}{\partial x} \int_{-H}^{0}\left(\frac{\partial \bar{u} \bar{v}}{\partial x}+\frac{\partial \bar{v} \bar{v}}{\partial y}\right) d z-\frac{\partial}{\partial y} \int_{-H}^{0}\left(\frac{\partial \bar{u}}{\partial x}+\frac{\partial \bar{u} \bar{v}}{\partial y}\right) d z+\frac{\partial}{\partial x} \int_{-H}^{0}\left(\frac{\partial \overline{u^{\prime} v^{\prime}}}{\partial x}+\frac{\partial \overline{v^{\prime} v^{\prime}}}{\partial y}\right) d z \\
& -\frac{\partial}{\partial y} \int_{-H}^{0}\left(\frac{\partial \overline{u^{\prime} u^{\prime}}}{\partial x}+\frac{\partial \overline{u^{\prime} v^{\prime}}}{\partial y}\right) d z
\end{aligned}
$$

The last term is the part of ocean circulation variability that travels upscale to produce time-mean residual vorticity and meridional transport.

Finally, it is physically meaningful to write BPT as the sum of a topographic vortex stretching term and both geostrophic and ageostrophic corrections. To do that, we can derive, as in Mertz and Wright (1992), the equation for the rate of change of vorticity of the depth- averaged (instead of depth-integrated) flow and by comparison with Eq. (2), we obtain

$$
\begin{aligned}
\mathrm{BPT}= & -\frac{f}{H}\left(U \frac{\partial H}{\partial x}+V \frac{\partial H}{\partial y}\right)-H \operatorname{curl}\left(\frac{\phi}{H}\right) \\
& +\frac{1}{H}\left[\frac{\partial H}{\partial y}\left(\tau_{x}^{w}-\tau_{x}^{b}\right)-\frac{\partial H}{\partial x}\left(\tau_{y}^{w}-\tau_{y}^{b}\right)\right] .
\end{aligned}
$$




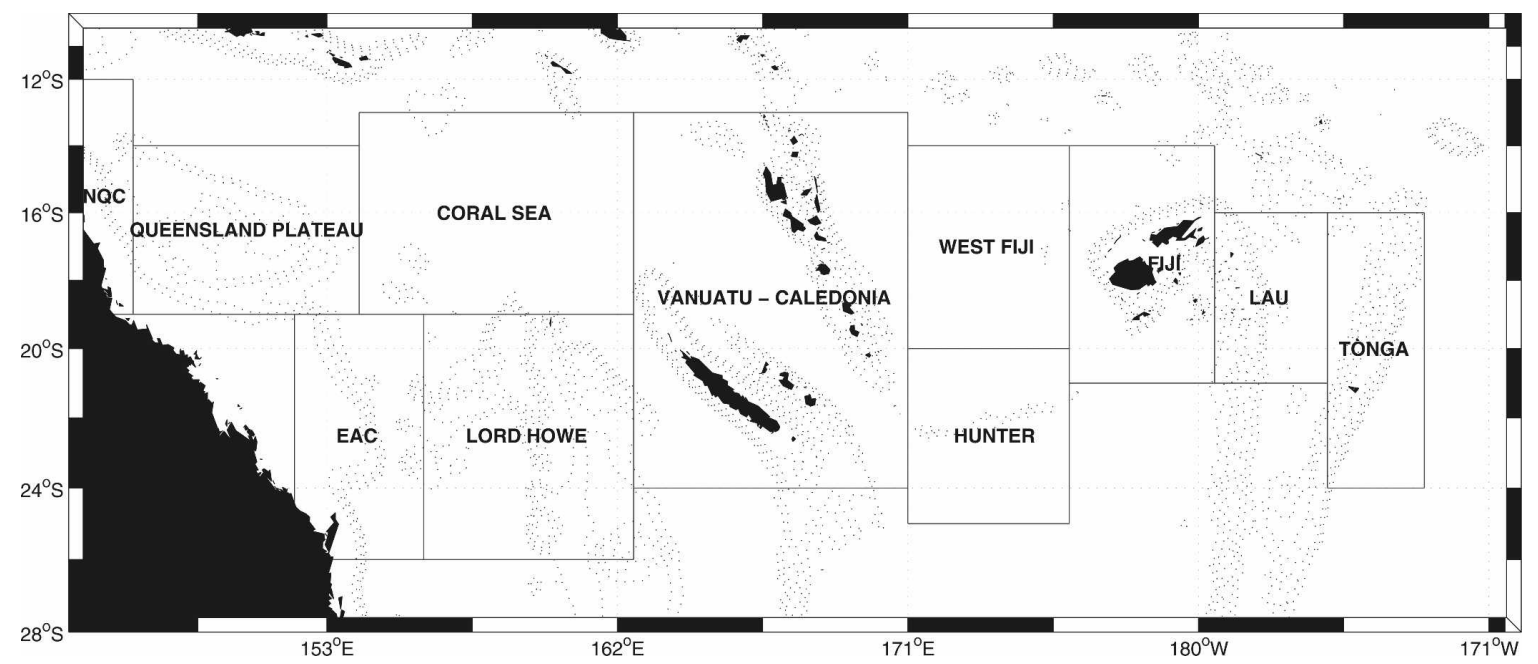

FIG. 9. Domain decomposition for vorticity budget. Bathymetry is plotted in dotted lines every $500 \mathrm{~m}$ between $500-$ and $2000-\mathrm{m}$ depth.

The first term on the right-hand side is the topographic vortex stretching, that is, the stretching (or squashing) of water columns associated with the cross-isobath transport. This term (hereafter called stretching) forces the flow to stay along $f / H$ lines in the homogeneous case when no additional forcing is in action. In a stratified ocean, topographic stretching is associated with cross-isobath bottom currents, not the depth-averaged flow; the other terms account for this difference. The second term is called the joint rffect of baroclinicity and relief (JEBAR), which corrects topographic steering due to baroclinicity by modifying the geostrophic flow at the bottom. The final term is an ageostrophic correction [slope-induced torque (SIT)], which is described in detail in Lee et al. (2001). It expresses the role of the cross-isobath Ekman flow when transport is directed along $f / H$ contours, and it is particularly important in western boundary currents.
Numerically, the budget was computed by taking the curl of both the depth-integrated and depth-averaged terms of the momentum equations (the latter for decomposition of BPT); the momentum terms are computed and stored during the simulation so that the resulting vorticity budgets are exactly balanced. Each component of the vorticity budget is evaluated in a selection of 11 subdomains representative of the various regimes encountered in the southwest tropical Pacific region (Fig. 9). Table 2 shows the area-averaged vorticity budget terms in each subdomain with detailed decomposition of advection and BPT terms. The model is in quasi equilibrium with only a small rate of change (not shown) of the mean vorticity. It can be seen that the Sverdrup balance is only dominant in areas between islands in relatively flat-bottom areas, such as west Fiji, Coral Sea, Lord Howe, and to a lesser extent the Hunter Fracture Zone (where wind curl is about $20 \%$

TABLE 2. Area-averaged vorticity components, defined in Eq. (2). The scale factor is $1.10^{12}$ (units are $\mathrm{m} \mathrm{s}^{-2}$ ).

\begin{tabular}{|c|c|c|c|c|c|c|c|c|c|c|c|}
\hline Vorticity terms & Tonga & Lau & Fiji & $\begin{array}{l}\text { West } \\
\text { Fiji }\end{array}$ & Hunter & Vanuatu-Caledonia & $\begin{array}{l}\text { Coral } \\
\text { Sea }\end{array}$ & $\begin{array}{l}\text { Lord } \\
\text { Howe }\end{array}$ & $\begin{array}{c}\text { Queensland } \\
\text { Plateau }\end{array}$ & EAC & NQC \\
\hline Beta & 654 & 154 & 68 & -15 & 103 & 100 & -29 & 54 & -39 & -470 & 353 \\
\hline Wind curl & 5 & -4 & -7 & -40 & 24 & -12 & -27 & 50 & -4 & 42 & -8 \\
\hline Bottom friction & -23 & 8 & 9 & -2 & 7 & 1 & -4 & 2 & 4 & 27 & 20 \\
\hline Advection & -18 & -23 & 161 & 12 & -1 & 222 & 10 & -11 & 26 & 4 & 79 \\
\hline Mean & 1 & -20 & 138 & 26 & 12 & 198 & 1 & 1 & -11 & 0 & 104 \\
\hline Eddy & -19 & -3 & 24 & -13 & -13 & 23 & 9 & -12 & 37 & 4 & -24 \\
\hline BPT & 689 & 174 & -95 & 14 & 72 & -111 & -8 & 14 & -64 & -541 & 264 \\
\hline Stretching & 3268 & 461 & -919 & -252 & 641 & 498 & -197 & -967 & 2775 & -589 & -2706 \\
\hline JEBAR & -2649 & -385 & 747 & 265 & -688 & -612 & 249 & 965 & -2241 & 1159 & 3095 \\
\hline SIT & 70 & 98 & 77 & 1 & 118 & 3 & -61 & 16 & -596 & -1110 & -125 \\
\hline
\end{tabular}


of the leading term). The areas of Tonga, Lau, Fiji, Vanuatu-Caledonia, EAC, NQC, and Queensland Plateau are all dominated by BPT or advection or a combination of both. Wind curl in these regions is $5 \%-10 \%$ of the leading terms, and even more negligible in Tonga, Lau, and NQC. As expected from simple potential vorticity considerations, the steep Tonga Ridge region (Tonga) drives a strong positive meridional transport due essentially to BPT. BPT is a relatively small residual of stretching and JEBAR, as topographic vortex stretching is almost (but not quite) compensated for by baroclinic effects. LAU presents a similar situation to TONGA; that is, the meridionally orientated Lau Ridge drives a large equatorward transport through topographic stretching (see also Fig. 4). The Fiji Islands present a different balance where advection is dominant and allows the flow to escape the topographic slope constraint, thereby keeping a northward direction (in spite of BPT being negative as the isobaths are orientated to the southwest when following flow direction). As already noted, the wind stress curl plays a more significant role west of Fiji. It is the leading term in the north (west Fiji), where it drives a poleward transport, consistent with the Sverdrup calculation presented in Fig. 3. However, it is interesting to note that BPT and advection reduce the effect of the wind curl here and give a more zonal direction to the transport than otherwise expected within the strict Sverdrup balance. In the south, around the sharp Hunter fracture zone, the leading term is again BPT, although wind curl plays a significant part in augmenting the topographic effect. This zone is another significant contributor to the general equatorward transport, diverting northward some of the zonal flow entering the South Fiji Basin (east of Hunter).

There is another type of balance in the VanuatuCaledonia zone. If these two groups of islands are globally contributing to the equatorward transport, $a d-$ vection is now the leading term while BPT makes a negative contribution. Looking more closely by decomposing into finer subdomains (not shown), it appears that the east side of the islands (where the flow starts interacting with topography) presents a similar balance to the Fiji case: the leading term is BPT, which drives the flow equatorward. Advection has strong values in places where the jets (NVJ and NCJ) separate from the northern tip of the islands; therefore, it plays an important role in separating part of the jets from the islands (as they escape $f / H$ contour lines). Nevertheless, southward transports in the leeward side of the islands are allowed by JEBAR, which appears there as the actual topographic forcing term. JEBAR drives southward transports along the northwest side of New Cale- donia and all along western Vanuatu. In the latter case, the transport is superimposed onto the two previously mentioned recirculation cells, leading to the $S$ shape of circulation that links the NVJ and NCJ (Fig. 4). The thermohaline forcing necessary to generate this kind of southward flow is probably similar to the generation mechanism at work in the Leeuwin Current off western Australia (McCreary et al. 1986). Density gradients are formed in the northwestern part of the islands as intense tracer advection by the jets put light tropical water masses in contact with denser subtropical Coral Sea Water masses.

The area between Australia and New Caledonia is again dominated by the Sverdrup balance. To the north, in the Coral Sea zone (excluding the Queensland Plateau) wind curl imposes a southward flow, while weak values of BPT and advection compensate for each other. In the Lord Howe Ridge zone to the south, the flow has a northward component, which is again essentially due to wind curl. BPT is larger there and the flow is deflected by the ridge, but not as much as expected. Looking at BPT components, we see a large stretching value, but it is almost compensated for by JEBAR. This result is explained by a strong baroclinicity south of New Caledonia, where the strongest gradients between tropical and subtropical waters are observed (e.g., in CARS climatology). The Queensland Plateau is the last obstacle before the jets bifurcate on the Australian coast. In this zone, BPT imposes a southern flow, and then the transport is divided between NQC and EAC. The EAC balance is strongly dominated by BPT. However, one of the leading BPT components here is SIT (i.e., essentially the slope-induced bottom stress torque). The meaning of this term and its effect on subtropical western boundary currents is discussed in detail by Lee et al. (2001). To summarize, it is an ageostrophic correction to stretching occurring as crossisobath bottom Ekman currents are created by transport along isobaths. SIT appears as the leading vorticity term driving poleward flow in subtropical western boundary currents, as shown by Lee et al. (2001) and confirmed here for the EAC. Advection is strong locally in EAC, but local values of opposite signs tend to compensate for each other in the area average. In the North Queensland Current, JEBAR is positive as in the EAC, but SIT is not as strong, which makes JEBAR the forcing term for an equatorward flow. BPT in the NQC is augmented by advection.

The separation of eddy and mean advection of vorticity shows that eddy is not a negligible part of the vorticity budget, although it remains relatively small when averaged over large areas. However, looking more closely at the budget within the recirculation cells 
areas (in the lee of Vanuatu, Fiji, and New Caledonia), eddy becomes the leading term (in the lee of Vanuatu and away from the coast, beta and eddy are an order of magnitude larger than the other terms) and confirms that these cells are strongly driven by nonlinear effects. In general, the eddy term has to compete with other forces, which have been previously described. West of Vanuatu, the coastal southern transport due to JEBAR is superimposed onto the recirculation cells, giving an $\mathrm{S}$ shape to the flow; in the northwest side of New Caledonia, a similar process produces a cyclonic circulation that compresses the anticylonic recirculation cell of the NCJ against its flanks; finally, the northern recirculation cell in the wake of Fiji is undermined by the superimposition of a southern flow generated by wind curl.

\section{b. Topographic sensitivity experiments}

The topographic smoothing procedure in sigmacoordinate models does not necessarily mean that these models misrepresent topography-flow interactions compared to geopotential coordinate models. We can argue that it is probably the opposite, even at coarse resolution, because of proper representation of the momentum bottom boundary condition (Marchesiello et al. 1998; Penduff et al. 2002). Either bathymetry smoothing (in terrain-following coordinate models) or discretization errors (in geopotential coordinate models) leads to underestimation of the control that topography can apply on the flow. This idea is mathematically expressed by the vortex stretching term in the vorticity budget being proportional to the topographic slope.

To confirm the vorticity budget results and further investigate the effect of topography on the barotropic flow, we present a series of sensitivity experiments at $1 / 6^{\circ}$ resolution. The model bottom topography is produced with slope parameter values $r=0.20$ (standard case) and $r=0.15$ (smoothed topography). In the latter case, the larger scales of bathymetry remain, but the bottom slope is reduced significantly. Figure 10 shows the model solutions corresponding to the different choices of topography. The jets' characteristics (transport, size, position, and barotropic velocity) are presented in Table 3 to better quantify the differences between each experiment.

The topography experiment shows that smoothing the bathymetry decreases its effect on the circulation. With $r=0.15$, the solution in Fig. 10 resembles more the Sverdrup solution (Fig. 3). In particular, the flow is more evenly spread around the islands, owing to a transport reduction of the northern jets (by $1 \mathrm{~Sv}$ for the NFJ and NCJ; $3 \mathrm{~Sv}$ for the NVJ). This gives confirma- tion that the general northern shift of the SEC is largely due to topographic steering. As a corollary to the general steering effect, the topographic slope also has a tendency to trap the flow and force it to narrow down over the slope area, with its velocity increasing. With topographic smoothing, the slope area is widened and the flow also becomes wider and weaker (Table 3). As a result, recirculation cells formed by nonlinear rectification almost disappear in the simulation with smooth bathymetry (this is addressed in the next section).

Our results suggest that the Tonga Ridge may play a significant role in the northern shift of the SEC. To further investigate this point, we have chosen in a following experiment to selectively increase topographic smoothing in the region east of Fiji (i.e., east of $180^{\circ}$ ), where the slope parameter is set to $r=0.05$ (to avoid strong discontinuities at $180^{\circ}$, the topographies are blended between $179^{\circ} \mathrm{E}$ and $181^{\circ}$ using a simple linear function). In Fig. 10c, the streamfunction around the Tonga Ridge is smoothed as expected, which affects the jets around Fiji. The SFJ is stronger than in the standard case at the expense of the NFJ, which loses $2 \mathrm{~Sv}$. This in turn affects the flow around New Caledonia and particularly Vanuatu (the NVJ loses $2 \mathrm{~Sv}$ of transport, while the SCJ gains about $1 \mathrm{~Sv}$ ). The overall effect is similar to the smoothed topography case, which tends to indicate that the Tonga Ridge is indeed playing a key role in the southwest Pacific circulation. However, the absence of a strong control by the Tonga Ridge is partly compensated for by the bathymetry around New Caledonia and Vanuatu, which is able to redirect part of the flow to feed the northern jets (NCJ and NVJ transports are $1 \mathrm{~Sv}$ larger than in the smoothed case).

\section{c. Advection and nonlinear dynamics}

In this section, the role of advection and nonlinear dynamics in driving the barotropic circulation is investigated further by simply testing the sensibility of the solutions to the presence of nonlinear momentum advection. Figure 11a presents a solution of the $1 / 6^{\circ}$ simulation in which the advection terms of the momentum equation are null. By comparing with the full solution (Fig. 10a) it becomes evident that the advection terms have a significant role in compensating for topographic steering. In the linear solution, the flow is trapped more clearly by topographic slopes, including at smaller scales, giving an impression of noise. This steering effect is particularly obvious on the western side of Fiji, where advection allows all of the NFJ to separate from the coast and continue its zonal route (Fig. 10a). This is confirmation of the result given by the vorticity budget: topographic steering and advection terms have large 

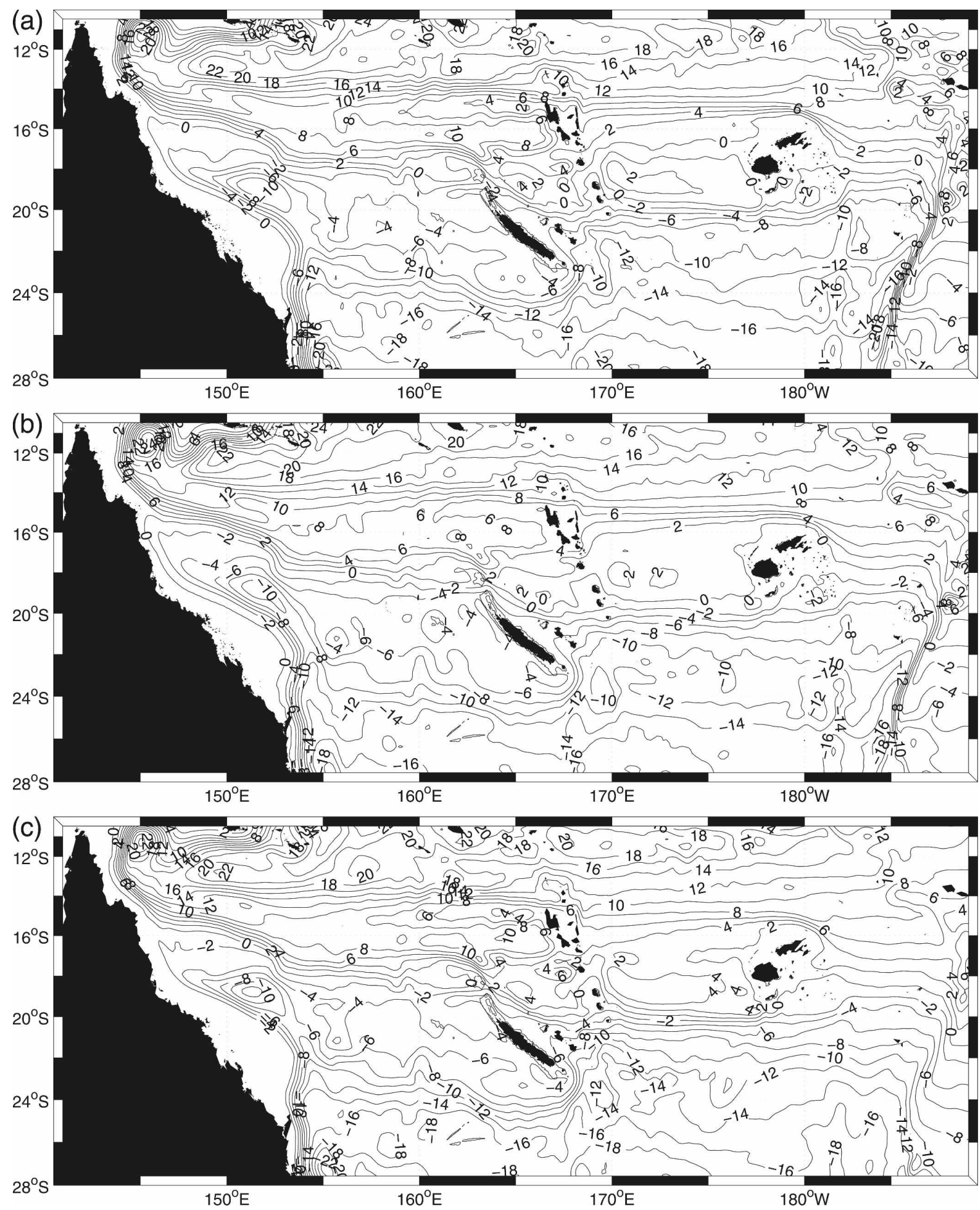

FIG. 10. Barotropic streamfunction at $1 / 6^{\circ}$ for different smoothing (a) $r=0.20$, (b) $r=0.15$, and (c) $r=0.20 / 0.05$.

regional and local values that tend to balance each other. Topographic steering is only partially attenuated by baroclinic effects and remains a dominant term at the local and regional scale where it is balanced by advection terms. The advection process therefore pro- vides yet another means of escaping the $f / H$ contour lines imposed by potential vorticity conservation. This result is in fact very consistent with the vorticity budget analysis presented by Wells and de Cuevas (1995) for the Antarctic Circumpolar Current, but it has never 
TABLE 3. Jets characteristic for various topography smoothing at $1 / 6^{\circ}$ resolution: $r=0.20$ (standard topography); $r=0.15$ (smoothed topography); smoothed Tonga ( $r=0.20$ west of $180^{\circ}$ and $r=0.05$ east of $\left.180^{\circ}\right)$. Jets' characteristics are transport (Sv), size (degree), position (latitude of jet center), and barotropic velocity $U_{\mathrm{bar}}\left(\mathrm{cm} \mathrm{s}^{-1}\right)$. NCJ and $\mathrm{NVJ}$ are estimated at $158^{\circ} \mathrm{E}, \mathrm{SCJ}$ at $162^{\circ} \mathrm{E}$, and SFJ and $\mathrm{NFJ}$ at $173^{\circ} \mathrm{E}$.

\begin{tabular}{|c|c|c|c|c|c|c|}
\hline Topography smoothing & Jets & SCJ & NCJ & NVJ & SFJ & NFJ \\
\hline \multirow{4}{*}{$r=0.20$} & Transport & -8.6 & -11.0 & -13.5 & -11.7 & -11.3 \\
\hline & Size & 1.8 & 1.9 & 2.1 & 2.2 & 2.1 \\
\hline & $U_{\text {bar }}$ & -3.2 & -1.6 & -1.7 & -1.6 & -1.6 \\
\hline & Position & -24.0 & -17.4 & -14.0 & -20.3 & -14.6 \\
\hline \multirow[t]{4}{*}{$r=0.15$} & Transport & -7.7 & -10.3 & -10.3 & -11.2 & -10.1 \\
\hline & Size & 1.8 & 2.4 & 2.4 & 2.7 & 2.3 \\
\hline & $U_{\mathrm{bar}}$ & -2.9 & -1.3 & -1.2 & -1.3 & -1.3 \\
\hline & Position & -24.0 & 17.8 & -13.8 & 20.3 & -14.7 \\
\hline \multirow[t]{4}{*}{ Smoothed Tonga $(r=0.05)$} & Transport & -9.4 & -11.3 & -11.6 & -14.2 & -9.3 \\
\hline & Size & 1.8 & 2.1 & 2.1 & 2.3 & 2.9 \\
\hline & $U_{\text {bar }}$ & -3.4 & -10.5 & -1.4 & -1.8 & -0.9 \\
\hline & Position & -24.7 & -17.5 & -13.9 & -20.3 & -15.0 \\
\hline
\end{tabular}
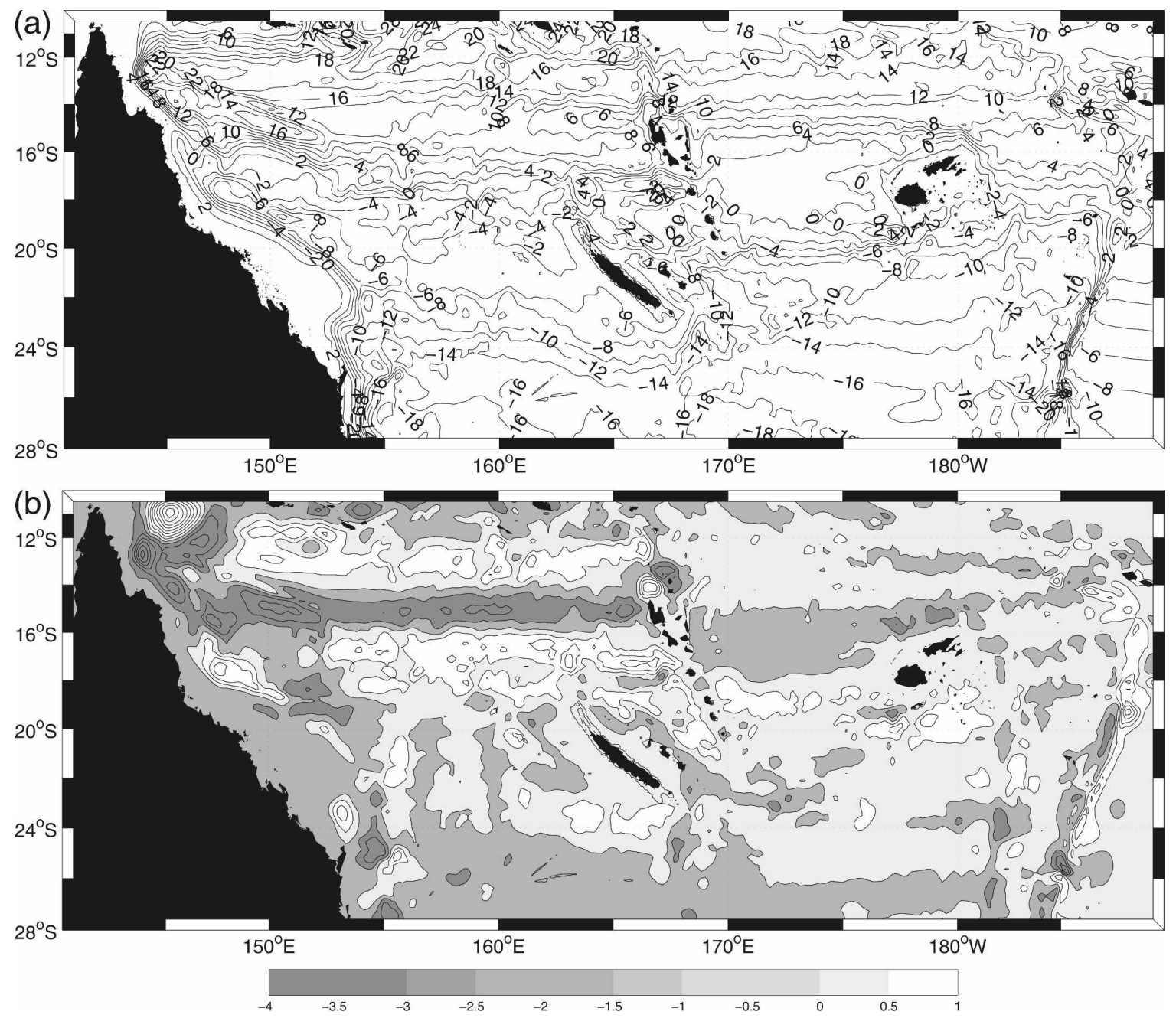

FIG. 11. (a) Linear ROMS solutions with bottom topography at $1 / 6^{\circ}$ resolution. (b) Difference between nonlinear and linear solutions (the nonlinear solution is presented in Fig. 9). 
been clearly acknowledged for tropical areas of the world.

We have just described a basically linear advection process, compensating for topographic steering. The role of nonlinearity appears in a rectification process, which involves the eddy advection components of the vorticity budget. Comparison between Figs. 10a, 11a shows that zonally elongated recirculation cells are generated in the nonlinear case only. In Fig. 10b, presenting the streamfunction difference between linear and nonlinear cases, the recirculation patterns appear as a major large-scale rectification product, particularly in the wake of Vanuatu. The rectification process tends to increase the jets transport and generates a counter flow in a recirculation pattern, which is characterized by a large contribution of eddy advection to the mean depth-integrated vorticity (section 5a). The mechanisms of rectification are probably complex here as they involve an externally maintained jet and strong topographic constraint; their investigation will therefore require further studies.

\section{d. Sensitivity to model resolution}

The robustness of numerical solutions requires convergence of these solutions as the resolution is increased. A usual condition for convergence is that truncation errors from discretization methods decrease with refined resolution, but other aspects have to be considered because of subgrid-scale physics parameterizations. As the grid size decreases, small-scale processes (which are improperly parameterized at lower resolution) become better resolved and may lead to changes in the equilibrium state. In addition, at the range of spatial resolution that is considered here, the topography (in particular the continental slope) often needs to be smoothed to keep $\Delta h / 2 h$ lower than the slope parameter value. Where smoothing is needed, the topographic slope (hence topographic vortex stretching) varies inversely to the spatial resolution. A natural test for the robustness of our solution is to compare simulations at different resolutions (Table 1).

Some of the outcome from the test of resolution sensitivity can be partly anticipated, using the knowledge gained about the effects of topography and nonlinear physics. Increasing the resolution tends to produce narrower jets, which are stronger and have been shifted to a more northern position. The larger differences occur between $1 / 2^{\circ}$ and $1 / 6^{\circ}$ solutions where the amount of topographic smoothing changes rapidly with resolution (at $1 / 2^{\circ}$, the result is more comparable to a flat-bottom solution). Dipoles of recirculation within island wakes begin to appear at $1 / 4^{\circ}$ and become longer and stronger with increasing resolution. Interestingly, the largest differences occur between $1 / 6^{\circ}$ and $1 / 12^{\circ}$ solutions, showing that the NFJ and NCJ become much stronger in the latter case. Part of this evolution can be understood by considering the combined effects of topography and advection. At $1 / 12^{\circ}$, the topography has become steep enough in the area of Tonga and Lau Ridges to divert almost all the transport toward the NFJ, producing weaker SFJ and SCJ. As the resolution increases, the topographic slope is also narrower, trapping the SEC to form stronger, narrower jets. This evolution, combined with increased nonlinear behavior leads the model to produce stronger rectified flow, augmenting the jets transport. This is particularly apparent on both sides of the NCJ, which also benefits from topographic steering of NFJ and SFJ branches.

From the above analysis, we can conclude that the combined effects of nonlinear advection and topographic steering are not completely settled and leave us to reflect to how these effects would end at even higher resolution. However, the general pattern of islandinduced barotropic jets appears stable and the resolution sensitivity experiments certainly confirm the robustness of our result concerning the role of topography in generating and steering branches of the SEC and the role of nonlinear rectification in augmenting their transport.

\section{Conclusions}

In this paper, we have investigated the role of topography and advection in modifying the South Equatorial Current circulation in the southwest Pacific. The eastern Pacific (east of Tonga) is characterized by relatively smooth topography contrasting with the western Pacific's rugged and steep topography. Therefore, in the eastern Pacific, the Sverdrup balance, which assumes infinite-depth bathymetry, may provide a relevant steady, barotropic, inviscid, linear solution for the SEC. However, as the flow enters the southwest Pacific region, we demonstrate in this study that the Sverdrup balance becomes only marginally valid. The barotropic flow becomes strongly affected by the topography and as a result produces narrow zonal jets that are located farther north than expected by the Sverdrup theory, even when Godfrey's island rule is included. The North Fiji, North Vanuatu, and North Caledonian jets appear as the strongest jets in the present simulations.

The island rule assumes that the closure of vorticity balance is provided only in western boundary current regions by lateral friction (on the east side of islands 
and continents). Our study shows that the balance is more complicated. The main local depth-integrated vorticity balance throughout almost the whole region is between bottom pressure torque and advection terms that tend to cancel each other. The BPT is itself a combination of large-magnitude components of opposite signs, mainly the stretching and JEBAR terms. The effect of topography is therefore considerably smoothed by baroclinicity and advection, but not to the point of total compensation as generally admitted for the interior ocean. The remaining tendency provides a strong departure from the Sverdrup balance. Another effect of nonlinear advection is flow rectification of the jets' fluctuations. Here, rectification takes the form of zonally elongated dipole circulations in the leeward side of islands, and it is Vanuatu and Fiji that are mainly affected. Rectification is also revealed in our budget analysis as an eddy vorticity forcing.

Our sensitivity experiments confirm the subtle relationship between slope-generated effects and advection, which allows changes of dynamical regimes as resolution is increased. It also appears that there is a remaining sensitivity to resolution that could be further explored with even higher resolution. Perhaps future experimentation may lead us to locally modulate our conclusions concerning high-resolution wind structure associated with island wind wakes (poorly resolved by the half-degree QuikSCAT data). Following conclusions from Hawaiian studies (Xie et al. 2001), betterresolved island wind wakes may produce eastward recirculations in the lee of islands, which would add to the eddy-driven recirculation shown in the present study.

Nevertheless, our sensitivity experiments, together with model-data comparisons and model intercomparisons, suggest that our regional model solution at $1 / 12^{\circ}$ resolution is robust and provides a strong basis to study the connectivity between equatorial and extraequatorial regions of the South Pacific, with the goal of gaining a greater understanding of Pacific interannual variability modulations.

Acknowledgments. We appreciate financial support from the IRD. In particular, the PC cluster used for the ROMS simulations was financed through IRD's scientific computing effort project SPIRALES. We thank Russ Davis for sharing the spray glider data, William Kessler for helping with glider data processing, Beverly de Cuevas for sharing the output from the U.K. Ocean Circulation and Advanced Modeling Project (OCCAM), and the OPA modelling team at LOCEAN for sharing the ORCA05 model output. Finally, we thank Pierre Dutrieux and Christophe Menkes for useful discussions.

\section{REFERENCES}

Barnier, B., L. Siefried, and P. Marchesiello, 1995: Thermal forcing for a global ocean circulation model using a three-year climatology of ECMWF analyses. J. Mar. Syst., 6, 363-380.

Beckmann, A., and D. B. Haidvogel, 1993: Numerical simulation of flow around a tall isolated seamount. Part I: Problem formulation and model accuracy. J. Phys. Oceanogr., 23, $1737-$ 1753.

Bratcher, A. J., and B. S. Giese, 2002: Tropical Pacific decadal variability and global warming. Geophys. Res. Lett., 29, 1918, doi:10.1029/2002GL015191.

Cane, M. A., V. M. Kamenkovich, and A. Krupitsky, 1998: On the utility and disutility of JEBAR. J. Phys. Oceanogr., 28, 519526.

Coward, A. C., and B. A. de Cuevas, 2005: The OCCAM 66 level model: Model description, physics, initial conditions, and external forcing. Southampton Oceanography Centre Internal Rep. 99, 83 pp.

Da Silva, A. M., C. C. Young, and S. Levitus, 1994: Algorithms and Procedures. Vol. 1, Atlas of Surface Marine Data 1994, NOAA Atlas NESDIS 6, 83 pp.

Dunn, J. R., and K. R. Ridgway, 2002: Mapping ocean properties in regions of complex topography. Deep-Sea Res., 49, 591604.

Fukumori, I., T. Lee, B. Cheng, and D. Menemenlis, 2004: The origin, pathway, and destination of the Niño-3 region waters. J. Phys. Oceanogr., 34, 582-604.

Giese, B. S., C. Urizar, and N. S. Fuckar, 2002: Southern Hemisphere origins of the 1976 climate shift. Geophys. Res. Lett., 29, 1014, doi:10.1029/2001GL013268.

Gill, A. E., 1982: Atmosphere-Ocean Dynamics. Academic Press, $662 \mathrm{pp}$.

Godfrey, S. J., 1989: A Sverdrup model of the depth-integrated flow for the world ocean allowing for island circulation. Geophys. Astrophys. Fluid Dyn., 45, 89-112.

Gourdeau, L., W. S. Kessler, R. E. Davis, J. Sherman, C. Maes, and E. Kestenare, 2008: Zonal jets entering the Coral Sea. J. Phys. Oceanogr., 38, 715-725.

Hellerman, S., and M. Rosenstein, 1983: Normal monthly wind stress over the world ocean with error estimates. J. Phys. Oceanogr., 13, 1093-1104.

Huang, B., and Z. Liu, 1999: Pacific subtropical-tropical thermocline water exchange in the National centers for Environmental Prediction ocean model. J. Geophys. Res., 104, 11 065-11 076.

Hughes, C. W., 2002: Zonal jets in and near the Coral Sea, seen by altimetry. Geophys. Res. Lett., 29, 1330, doi:10.1029/ 2001 GL014006.

Kessler, W. S., and L. Gourdeau, 2006: Wind-driven zonal jets in the South Pacific Ocean. Geophys. Res. Lett., 33, L03608, doi:10.1029/2005GL025084.

— and _ 2007: The annual cycle of circulation of the southwest subtropical Pacific analyzed in an ocean GCM. J. Phys. Oceanogr., 37, 1610-1627.

Large, W. G., J. C. McWilliams, and S. C. Doney, 1994: Oceanic vertical mixing: A review and a model with a nonlocal boundary layer parameterization. Rev. Geophys., 32, 363-403.

Lee, S.-K., J. L. Pelegri, and J. Kroll, 2001: Slope control in western boundary currents. J. Phys. Oceanogr., 31, 3349-3360.

Luo, J.-J., S. Masson, S. Behera, P. Delecluse, S. Gualdi, A. Navarra, and T. Yamagata, 2003: South Pacific origin of the decadal ENSO-like variation as simulated by a coupled 
GCM. Geophys. Res. Lett., 30, 2250, doi:10.1029/ 2003 GL018649.

Maes, C., L. Gourdeau, X. Couvelard, and A. Ganachaud, 2007: What are the origins of the Antarctic Intermediate Waters transported by the North Caledonian Jet? Geophys. Res. Lett., 34, L21608, doi:10.1029/2007GL031546.

Marchesiello, P., B. Barnier, and A. P. de Miranda, 1998: A sigmacoordinate primitive equation model for studying the circulation in the South Atlantic. Part II: Meridional transports and seasonal variability. Deep-Sea Res. I, 45, 573-608.

_ J. C. McWilliams, and A. Shchepetkin, 2001: Open boundary conditions for long-term integration of regional oceanic models. Ocean Modell., 3, 1-20.

,-- , and -2003 : Equilibrium structure and dynamics of the California Current System. J. Phys. Oceanogr., 33, 753783.

Mata, M. M., M. Tomczak, S. Wijffels, and J. A. Church, 2000: East Australian Current volume transports at $30^{\circ} \mathrm{S}$ : Estimates from the World Ocean Circulation Experiment hydrographic sections PR11/P6 and the PCM3 current meter array. J. Geophys. Res., 105, 28 509-28 526.

McCreary, J. P., S. R. Shetye, and P. K. Kundu, 1986: Thermohaline forcing of eastern boundary currents: With application to the circulation off the west coast of Australia. J. Mar. Res., 44, 71-92.

Mertz, G., and D. G. Wright, 1992: Interpretation of the JEBAR term. J. Phys. Oceanogr., 22, 301-305.

Nakano, H., and H. Hasumi, 2005: A series of zonal jets embedded in the broad zonal flows in the Pacific obtained in eddypermitting ocean general circulation models. J. Phys. Oceanogr., 35, 474-488.

Penduff, T., B. Barnier, M. A. Kerbiriou, and J. Verron, 2002: How topographic smoothing contributes to differences between the eddy flows simulated by sigma- and geopotentialcoordinate models. J. Phys. Oceanogr., 32, 122-137.

Penven, P., V. Echevin, J. Pasapera, F. Colas, and J. Tam, 2005: Averaged circulation, seasonal cycle, and mesoscale dynamics of the Peru Current System: A modeling approach. $J$. Geophys. Res., 110, C10021, doi:10.1029/2005JC002945.

_, P. Marchesiello, L. Debreu, and J. Lefevre, 2007: Software tools for pre- and post-processing of oceanic regional simulations. Environ. Model. Softw., 23, 660-662.

Qiu, B., D. A. Kho, C. Lumpkin, and P. Flament, 1997: Existence and formation mechanism of the North Hawaiian Ridge Current. J. Phys. Oceanogr., 27, 431-444.

Qu, T., and E. J. Lindstrom, 2002: A climatological interpretation of the circulation in the western South Pacific. J. Phys. Oceanogr., 32, 2492-2508.

Richards, K. J., N. A. Maximenko, F. O. Bryan, and H. Sasaki, 2006: Zonal jets in the Pacific Ocean. Geophys. Res. Lett., 33, L03605, doi:10.1029/2005GL024645.

Ridgway, K. R., and J. R. Dunn, 2003: Mesoscale structure of the East Australian Current System and its relationship with topography. Prog. Oceanogr., 56, 189-222.

Sasaki, H., and M. Nonaka, 2006: Far-reaching Hawaiian Lee Countercurrent driven by wind-stress curl induced by warm SST band along the current. Geophys. Res. Lett., 33, L13602, doi:10.1029/2006GL026540.

Shchepetkin, A. F., and J. C. McWilliams, 1998: Quasi-monotone advection schemes based on explicit locally adaptive dissipation. Mon. Wea. Rev., 126, 1541-1580.

—, and — , 2003: A method for computing horizontal pressure-gradient force in an ocean model with a nonaligned vertical coordinate. J. Geophys. Res., 108, 3090, doi:10.1029/ 2001JC001047.

—_ and — 2005: The regional oceanic modeling system (ROMS): A split-explicit, free-surface, topographyfollowing-coordinate oceanic model. Ocean Modell., 9, 347 404.

Song, Y., and D. B. Haidvogel, 1994: A semi-implicit ocean circulation model using a generalized topography-following coordinate system. J. Comput. Phys., 115, 228-244.

Stanton, B., D. Roemmich, and M. Kosro, 2001: A shallow zonal jet south of Fiji. J. Phys. Oceanogr., 31, 3127-3130.

Wajsowicz, R. C., 1993: The circulation of the depth-integrated flow around an island with application to the Indonesian Throughflow. J. Phys. Oceanogr., 23, 1470-1484.

Webb, D. J., 2000: Evidence for shallow zonal jets in the south equatorial current region of the southwest Pacific. J. Phys. Oceanogr., 30, 706-720.

Wells, N. C., and B. A. de Cuevas, 1995: Depth-integrated vorticity budget of the Southern Ocean from a general circulation model. J. Phys. Oceanogr., 25, 2569-2582.

Xie, S.-P., W. T. Liu, and Q. Liu, 2001: Far-reaching effects of the Hawaiian Islands on the Pacific Ocean-Atmosphere System. Science, 292, 2057-2060. 